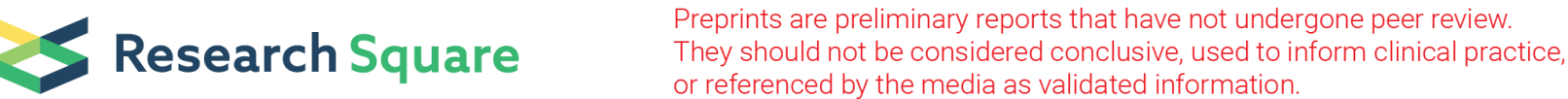

\section{Revelation of candidate genes and molecular mechanism of reproductive seasonality in carp fish (Labeo rohita Ham) by RNA sequencing}

\section{Sarika Jaiswal}

Indian Agricultural Statistics Research Institute

\section{Samiran Nandi}

Central Institute of Freshwater Aquaculture

\section{Mir Iquebal}

Indian Agricultural Statistics Research Institute

\section{Rahul Jasrotia}

Indian Agricultural Statistics Research Institute

\section{Sunita Patra}

Central Institute of Freshwater Aquaculture

\section{Gayatri Mishra}

Central Institute of Freshwater Aquaculture

\section{Uday Udit}

Central Institute of Freshwater Aquaculture

\section{Dinesh Sahu}

Central Institute of Freshwater Aquaculture

\section{U Angadi}

Indian Agricultural Statistics Research Institute

\section{Prem Meher}

Central Institute of Freshwater Aquaculture

\section{Padmanav Routray}

Central Institute of Freshwater Aquaculture

\section{Jitendra Sundaray}

Central Institute of Freshwater Aquaculture

\section{Dhananjay Verma}

Central Institute of Freshwater Aquaculture

\section{Paramananda Das}

Central Institute of Freshwater Aquaculture

\section{Pallipuram Jayasankar}

Central Institute of Freshwater Aquaculture

Anil Rai 
Indian Agricultural Statistics Research Institute

Dinesh Kumar ( $\nabla$ dinesh.kumar@icar.gov.in )

Indian Agricultural Statistics Research Institute

\section{Research Article}

Keywords: Labeo rohita, circannual, Cyprinid, biological clock genes, marker, reproductive seasonality Posted Date: December 10th, 2020

DOI: https://doi.org/10.21203/rs.3.rs-118092/v1

License: (c) (i) This work is licensed under a Creative Commons Attribution 4.0 International License. Read Full License 


\section{Abstract}

\section{Background}

Carp fish, rohu (Labeo rohita Ham) is important freshwater aquaculture species of South-East Asia having seasonal reproductive rhythm. There is no holistic study at transcriptome level revealing key candidate genes involved in such circannual rhythm regulated by biological clock genes (BCGs). Seasonality manifestation has two contrasting phases of reproduction, i.e., post-spawning regression and initiation of gonadal activity appropriate for discovery of associated candidate genes. It can be deciphered by RNA sequencing of tissues involved in BPGL (Brain-Pituitary-Gonad-Liver) axis controlling seasonality. How far such BCGs of this fish are evolutionarily conserved across different phyla is unknown. Such study can be of further use to enhance fish productivity as seasonality restricts seed production beyond monsoon season.

\section{Result}

A total of $\sim 150 \mathrm{~Gb}$ of transcriptomic data of four tissues viz., BPGL were generated using Illumina TruSeq. De-novo assembled BPGL tissues revealed 75554 differentially expressed transcripts, 115534 SSRs, 65584 SNPs, 514 pathways, 5379 transcription factors, 187 mature miRNA which regulates candidate genes represented by 1576 differentially expressed transcripts which are available in the form of web-genomic resources. Findings were validated by qPCR. This is first report in carp fish having 32 BCGs found widely conserved in fish, amphibian, reptile, birds, prototheria, marsupials and placental mammals. This is due to universal mechanism of rhythmicity in response to environment and earth rotation having adaptive and reproductive significance.

\section{Conclusion}

This study elucidates evolutionary conserved mechanism of photo-periodism sensing, neuroendocrine secretion, metabolism and yolk synthesis in liver, gonadal maturation, muscular growth with sensory and auditory perception in this fish. Study reveals fish as a good model for research on biological clock besides its relevance in reproductive efficiency enhancement.

\section{Background}

Reproductive rhythm of fish varies from prolific breeders to seasonal breeders. Though prolific breeder like common carp and zebra fish breed independent of season but vast majority of the freshwater fishes of Indian subcontinent breed seasonally during the monsoon season (June-August) when rainfall is heaviest [1]. This rhythm reflects evolution of differential biological clock.

Major carp of South-East Asia like Labeo rohita (Hamilton), which is an important freshwater aquaculture species having economic, ecological and cultural attributes would be a best model to study how seasonal manifestation of reproductive behavior is controlled by circannual biological clock. This also indicates 
that species differentiation in evolution of reproductive behaviour is an outcome of both genome $(\mathrm{G})$ and environment (E) interactions.

In seasonal reproductive behaviour, BPGL (Brain-Pituitary-Gonad-Liver) axis and fish biological clock is well known having entrainment of its biological clock with environment, temperature and food availability [2]. Master biological clock in fish perceives the environmental or exogenous cue to entrain the other biological clock of peripheral tissues to manifest seasonal reproductive changes for annual breeding cycle. In case of fish it is well known that reproductive axis is controlled by BPG [3]. Most active liver metabolism has been found in fish having potential to acquire bigger (upto $6 \mathrm{feet}, 45 \mathrm{~kg}$ ) size thus liver transcriptome should be included in study of gonadal maturation by BPG (Brain-Pituitary-Gonad) axis [4]. Biological rhythm of seasonal breeding in fish is regulated by neuro-endocrine system, controlled by BPGL axis [5]. In order to decipher candidate genes regulating seasonal fish breeding RNA sequencing of associated tissues are imperative. Such data can be used to construct gene regulatory networks (GRNs) to depict process of cell differentiation, metabolism, cell cycle and signal transduction in the biological system. Understanding dynamics of these networks can shed light on mechanism of reproductive seasonality.

Earlier attempt to investigate gene expression associated with seasonal breeding in carp fish, rohu were confined to limited genes $(<200)$ by microarray approach, limited ESTs $(<5000)$ comparing preparatory and post-spawning stages along with limited genomic resources in form of SSR $(<250)$ but without SNP [6]. In another such investigation by RNA Seq approach [7] limited reproductive genes were identified. Though this study enlists reproductive genes which are based on pooled RNA samples (of twelve tissues related to digestive and reproductive system) without differentially expressed genes (DEGs), thus lacks in identification of key candidate genes associated with reproductive seasonality. Even in one of the largest global consortium mode fish transcriptome project, FishT1K (https://www.fisht1k.org/) which is covering 124 species representing 46 orders, having six cypriniformes species but there is no data on carp fish, Labeo rohita which can be used as genomic resource to discover seasonality controlling genes along with biological clock genes (BCGs). RNA seq data of BPGL axis involved tissues can not only be used for evolutionary knowledge discovery but they can also be used for genome assembly and annotation of this fish in future. A tissue-wise RNA sequencing comparison between two physiologically contrasting phases i.e., post-spawning regression (PSR) and initiation of gonadal activity (IGA) can decipher key candidate genes and their regulatory networks.

Seasonal reproductive rhythm is influenced by day length/ photoperiod, ambient temperature and food availability [2]. Since circannual biological rhythm of seasonal reproduction is controlled by biological clock, regulating BPGL axis, thus RNA seq approach can also be used to discover biological clock genes. Since biological clock originated 2.5 billion years ago and it is well conserved across all phyla i.e., from lower vertebrates to higher vertebrates, thus comparative genomics approach can be used for in silico discovery of such genes. Differential expression of such biological clock genes across different tissues involved in seasonal reproduction can be treated as direct evidence for their role and existence in the particular species. Since biological clocks controlling seasonality are known to offer several advantages 
in process of speciation thus comparison of such genes using whole genome sequence data of each phyla can throw light on evolutionary significance in terms of adaptation [8].

Present work aims at 1) Discovery of candidate genes of seasonal biological rhythm of breeding and gene regulatory networks. 2) Investigation of differentially expressed biological clock genes (BCGs). 3) Finding the extent of evolutionary conservation of these BCGs across jawless fish, cartilaginous fish (whale shark), bony fishes (zebrafish and European carp), amphibia, bird, reptile, monotreme (egg laying mammal), marsupials (young born) and placental mammals using comparative analysis of whole genome sequences of each phyla. 4) Developing a genomic resource database of evolutionary conserved BCGs of each phyla along with seasonality associated candidate genes of carp fish, Labeo rohita (rohu).

\section{Results And Discussion}

\section{Reproductive phase identification by estimation of GSI and histology}

Histological analysis of ovarian tissue of PSR and IGA phases revealed the changes in response to seasonality. Primary ovarian follicles (POF), smaller in size were present during PSR dormancy (lower GSI). During IGA phase having higher GSI maturation of secondary ovarian follicles (SOF) with larger size was seen in the histological photomicrographs, revealing conspicuous seasonal differences (Figure 1). It confirmed the accuracy of tissues collected in the investigation. Similar histological attributes of ovarian development stages has also been reported in other fishes like zebrafish (Koç 2008).

Like other Indian teleosts, the reproductive cycle of $L$. rohita may be divided into four stages, viz., preparatory period (February-April), pre-spawning period (May-June), spawning period (July-August), and post-spawning period (September-January) and at each stage gonads show discrete changes [9]. Generally in an adult rohu female, the ovary remains quiescent and almost inactive during last part of post spawning period also called post spawning regression (PSR). With gradual increase in day length and temperature, there is increase of gonadal activity (IGA) for preparatory period. This confirmed that these two reproductive contrasting phases, viz., PSR and IGA as most appropriate transcriptomic data points to study the changes that happens at the molecular level during onset of gonad maturation in this tropical species manifesting biological rhythm of seasonal breeding.

\section{Pre-processing and assembly}

A total of $\sim 150 \mathrm{~Gb}$ of transcriptomic data of four tissues viz., BPGL were pre-processed before assembly by removing 1098340 poor quality reads. The remaining 305461765 high quality reads were subjected to de novo assembly. A total of 440665 transcripts were generated with $k$-mer size 25 . The minimum contig length was $201 \mathrm{bp}$ and maximum of $19331 \mathrm{bp}$ with average length of $867 \mathrm{bp}$. N50 was found to be 1850 bp and total GC content as $42.94 \%$ (Table 1). Figure 2 shows the sequence length distribution of the data under study. A total of 45019 unigenes were involved in the formation of isoforms. Numbers of isoforms were found in single unigenes ranging from 2 to 30 . 
DEGs were obtained by comparison of four transcriptomics datasets, viz., IGA[BR] vs. PSR[BR], IGA[PIT] vs. PSR[PIT], IGA[OVA] vs. PSR[OVA] and IGA[LIV] vs. PSR[LIV] tissues using edgeR tool with standard cutoff threshold parameters i.e., FC log $2>2$ or $<-2$ and FDR of 0.05 . A total of 35840, 21767, 31097 and 14558 DEGs were identified for IGA[BR] vs. PSR[BR], IGA[PIT] vs. PSR[PIT], IGA[OVA] vs. PSR[OVA] and IGA[LIV] vs. PSR[LIV] respectively. The upregulated and downregulated DEGs from the datasets are presented in Table 2. Expression profiling and hierarchical clustering of DEGs of all tissue specific comparison were shown in the form of heatmaps. MA plots and volcano plots of differentially expressed genes were generated by edgeR tool which showed the red color dots are differentially expressed and black color dot represents the non-DEGs and all these plots were generated on the basis of log2 fold change values (Supplementary file 1).

Venn diagram was constructed to identify the unique and common unigenes among all tissue specific differentially expressed genes (Figure 3). Venn diagram was constructed to identify the unique and common unigenes among all tissue specific candidate genes. A total of 705 unigenes were found common in all datasets of tissue specific DEGs. We found 20845, 9388, 17739 and 5758 unigenes as unique in IGA[BR] vs. PSR[BR], IGA[PIT] vs. PSR[PIT], IGA[OVA] vs. PSR[OVA] and IGA[LIV] vs. PSR[LIV], respectively.

\section{Annotations and gene ontology classification of DEGs}

Sequence similarity search of differentially expressed genes of all tissue specific comparison was performed by standalone Blast using the NCBI non-redundant (NR) database

(ftp://ftp.ncbi.nlm.nih.gov/blast/db/). We found $79.27 \%, 84.38 \%, 82.87 \%$ and $86.44 \%$ of differentially expressed genes of IGA[BR] vs. PSR[BR], IGA[PIT] vs. PSR[PIT], IGA[OVA] vs. PSR[OVA] and IGA[LIV] vs. PSR[LIV] having blast match, respectively (Supplementary file 2: Uploaded at "Supplements" tab of http://webtom.cabgrid.res.in//rsatdb/). Table 3 described the number of sequences which showed the blast hits, mapping, interproscan and annotations statistics for dataset under study.

DEGs from all tissue specific comparison were categorized into three sub division i.e. biological process, molecular function and cellular component (Supplementary file 3). Gene ontology and KEGG (Kyoto Encyclopaedia of Genes and Genomes) analysis were performed by using Blast2Go pro software $v 4.0$ [10]. Tissue specific DEGs were mapped to KEGG pathways and 131, 126, 130 and 124 pathways were found in IGA[BR] vs. PSR[BR], IGA[PIT] vs. PSR[PIT], IGA[OVA] vs. PSR[OVA] and IGA[LIV] vs. PSR[LIV], respectively (Supplementary file 4).

\section{Prediction of transcription factors controlling seasonality genes}

Transcription factor (TFs) plays very vital role in the expression of genes. We predicted Transcriptional factors (TFs) from Rohu (L. Rohita) against Danio rerio transcription sequences and data was retrieved from AnimalTFDB2.0 [11]. We found 2458, 1685, 2354 and 1225 transcriptions factor (TF's) in sets 
IGA[BR] vs. PSR[BR], IGA[PIT] vs. PSR[PIT], IGA[OVA] vs. PSR[OVA] and IGA[LIV] vs. PSR[LIV], respectively (Supplementary file 5). Out of these transcription factors, 53 were found common in all the datasets. We also found 1234, 674, 1169 and 458 transcription factors as unique in all the tissue specific sets i.e., IGA[BR] vs. PSR[BR], IGA[PIT] vs. PSR[PIT], IGA[OVA] vs. PSR[OVA] and IGA[LIV] vs. PSR[LIV], respectively (Figure 4). Some of the TFs are known to regulate biological clock genes in flies and humans by acting as time switch genes [12]. We found some of these are well known to control BCGs and are also conserved even in this carp fish. Example of such TFs are clock, foxl, bmal, kiss, esr, prdm, of $x, m y c$, srebf, bhlh and $P A S$. These TF and/or BCGs regulates gene regulatory network (GRN) of BPGL axis manifesting circannual rhythm of breeding.

\section{Prediction of miRNA controlling seasonality genes}

Though 1637 microRNA have been identified and reported in mirRBase in nine fish species and most of them are widely conserved but still experimental identification of miRNAs in specific fishes are too less. In case of rohu there is no micro RNA reported so far. This is due to difficulty in isolation by cloning due to low expression, temporal expression and stability, tissue. Thus, computational identification of miRNAs binding site can be predicted and classification of the functional attributes of these miRNA can be done. Instead of isolating small RNA afresh, the same larger RNA can be used to predict specific binding site to have information without any additional cost and time. It has been well reported that molecular markers for egg quality and embryonic development is a potential biomarker in rainbow trout [13]. Moreover, miRNAs are also reported to be involved in oocyte and early embryo $[14,15,16]$ and gonadal development [17].

We identified miRNA target prediction of all tissue specific differential expressed genes with 1637 mature miRNAs of nine fish species with cut-off threshold of total score at 1000 and total energy $>-14 \mathrm{kcal} / \mathrm{mol}$. We obtained 790, 641, 764 and 629 mature miRNAs that regulate 1444, 770, 1229 and 1044 differential expressed genes at tissue specific stages IGA[BR] vs. PSR[BR], IGA[LIV] vs. PSR[LIV], IGA[OVA] vs. PSR[OVA] and IGA[PIT] vs. PSR[PIT] (Table 4) (Supplementary table 6). From all the tissue specific stages, we identified several miRNAs which were involved in various developmental stages i.e. gonadal development, oocyte and early embryo, nervous system against all the nine fish species (Supplementary file 7).

\section{Discovery of putative markers of seasonality associated genes}

A total of 115534 putative SSR markers were mined from de novo assembly of transcriptome using MISA perl script. We found 89133, 35931, 13645, 3312, 73, 51 mononucleotides, dinucleotides, trinucleotides, tetranucleotides, pentanucleotides and hexanucleotides, respectively (Table 5, Supplementary file 8: Uploaded at "Supplements" tab of http://webtom.cabgrid.res.in//rsatdb/).

We obtained a total of 123994 and 120652 variants from IGA and PSR tissues samples, respectively against Danio rerio GRCz10 reference genome. A total of 99981 variants were found common in IGA and PSR transcriptomic sets. In heterologous mapping with species Danio rerio, maximum numbers of 
variants were found on chromosome number 5. Maximum numbers of variants were 7617 and 7238 in IGA and PSR, respectively. In de novo based mining, a total of 45098 and 43420 SNPs and Indels were obtained in IGA and PSR samples, respectively. Among this, 22934 SNPs and Indels were common. In IGA samples, unigenes number c144686_g1_i1 (polyprotein) were found maximum number of time i.e., 116 and in PSR samples, c144749_g1_i1 unigene was found abundantly i.e., 77. Unigene "c144749_g1_i1" might be a novel transcript, as it did not show any specific matched with NCBI blastx (uncharacterized protein). Stringent filtering criteria was used for the detection of SNPs and Indels, i.e., minimum 15x [18] read depth and quality of 30 were used. Annotations of detected variants were performed against Danio rerio GRCz10 reference and identified the region where maximum number of SNPs were present (Supplementary file 9: Uploaded at "Supplements" tab of http://webtom.cabgrid.res.in//rsatdb/).

\section{Gene regulatory network controlling seasonality}

A GRN depicts set of genes that interact with each other to control a specific cell function pertaining to a particular trait. Such studies are important to understand development, differentiation and response to environmental stimuli. By making such network of large number of DEGs can be further narrowed down [19]. SNPs of genes involved in GRN affects phenotype/trait [20] thus are valuable for eQTL discovery. Since prediction of the behaviour of GRN are rapid and economical than wet lab experiments, thus computational methods can be a valuable research tool [21]. GRN studies has been used to identify candidate genes associated with the traits [22]. Gene regulatory networks (GRN) is further controlled by transcription factor and microRNA [23].

The GRN models of brain, pituitary, gonad and liver tissues were represented by $21,35,46$ and 25 genes, respectively. Some of them were predicted as hub genes having similar protein-protein interaction. Magnitude of such genes expression can be correlated with trait of interest [24]. As not much information is available on seasonality aspect of these tissues, thus limited sample size transcriptomic data was used to develop "logical model" to have a basic picture of GRN reflecting qualitative attributes of genes involved in the network rather than precise quantitative relationship [25]. BPGL/BPG axis has already been reported with several candidate genes controlling reproduction and its synchronization with food availability and photoperiodism in farm fishes [26].

\section{GRN in brain controlling seasonality}

GRN in brain controlling seasonality was constructed using top 100 co-expressed genes to depict proteinprotein interactive network. Genes were selected at a cut off degree value of 167. A total of 20 hub genes were predicted having 8 up, 13 down regulated genes shown in Supplementary file 10. Since fish neuroendocrine system and brain is having very high similarity (82\%) with human brain [27], thus available literature can be used to understand and explain the GRN operating in brain manifesting seasonal breeding. GRN was found to control sensing of time by visual stimuli, neuro modulation, neuro translation, neurotransmitter synthesis and release, integration of light and temperature regulated circadian gene expression, melanocytes and growth and learning regulation of feeding behaviour. Specific role of predicted hub genes are summarized in table 6. 
Seasonality is synchronized by temperate latitudes, photoperiod, abundance of food, temperature and other environmental cues which are input to neuroendocrine output. Brain perceives the signal of photoperiod by melatonin pathway. Eyes are the only photoreceptive organs operating through pineal gland producing melatonin. Melatonin receptors are present in suprachiasmatic nuclei (SCN) which are the transducer of such signal acting as circadian rhythm pacemaker. Saccus vasculosus (SV) acts as a sensor of such seasonal changes in day length in fish as its removal affects the BPGL axis [28]. Photoperiod is sensed by SCN and transduced to give signal to thyroid for seasonal physiological events thus thyroid-stimulating hormone (TSH) and DIO gene also play role in seasonality [29].

There are two steps in cyclical phase of seasonality viz., PSR and IGA with slow and faster growth, respectively which is controlled by BPGL axis in rohu fish [30]. Such biological rhythm is even connected with fish auditory function for environmental cue required for reproduction and breeding [31].

\section{GRN in pituitary controlling seasonality}

In order to depict protein-protein interactive network in pituitary GRN was constructed using co-expressed genes in the tissue by selecting the genes at a cut off degree of 175. A total of 35 hub genes were regulating the network with 15 and 20 up and down regulated genes, respectively (Supplementary file 10). MAPK signalling pathway was found to control environmental signal mediation, gonadogenesis, retenoic acid pathway controlling gametogenesis, ovarian growth and gametogenesis, increase in cell size and proliferation, oocyte maturation and ovulation, control of BPGL axis for liver metabolism, skeletal muscle development and immunity control. The specific role of hub genes in controlling seasonality has been summarized in table 7. Due to extensive conservation between human and fish pituitary neuroendocrine system [32, we found very similar hub genes having well established role in mediating reproduction.

Pituitary plays a pivotal role in manifestation of seasonality of breeding in fish. The fish anterior pituitary secretes two gonadotrophin (GTH) hormones viz., GTH-I and GTH-II which are structurally similar to FSH and $\mathrm{LH}$, respectively. GTH-II in goldfish is reported to stimulate gonadal growth, steroidogenesis, ovulation and sperm release with seasonality [33. Pituitary regulates seasonality by variation in pituitary GnRH receptor activity and gonadal feedback mechanism in catfish and goldfish [34]. Teleost have two gonadotropins, viz., GtH beta I and II. Beta subunit synthesis is regulated by hypothalamic hormones and gonadal steroids. In pre-spawning and early maturing stage of fish beta I and in post spawning beta II predominates with seasonality. In tilapia, this activity is mediated by CAMP-PKA and PKC pathways [35] FSH and LH upregulates genes involved in steroid synthesis in fish [36]. This leads to growth of primary oocyte into secondary oocyte. FSH level remains increased in ovary along with FSH receptor gene expression in ovary from pre-spawning to post spawning transforming primary. During post spawning, i.e., vitellogenesis FSH continue to rise but during ovulation it declines with surge of LH [37].

\section{GRN in Gonad (Ovary) controlling seasonality}

100 top co-expressed genes were selected at a cut off degree of 175 to construct GRN operating in fish ovary. Ovarian GRN having 46 hub genes were found to have 23 up and 23 down regulated genes 
(Supplementary file 10). Hub gene activities were found to control mitogenic action of estrogen in grandulosa cell of ovary, growth of ovarian follicles, oocyte maturation, chondrocyte differentiation, prostaglandin synthesis, collagen synthesis and receptor mediated endocytosis. This reflects that neuroendocrine mechanism regulating reproduction through hypothalamo-pituitary-gonadal (HPG) axis is evolutionarily conserved in vertebrates [38]. All these neuroendocrine induced physiological events are coordinated by set of regulatory genes which are depicted in Supplementary file 10 and the role of various candidate genes/ hub genes identified in rohu fish ovary are shown in Table 8. Seasonal breeding fish, Labeo rohita has seasonal variation in ovarian development having seven distinct stages (phases) viz., Virgin/Immature, primary growth, perinucleolar, previtellogenic (yolk vesicle), vitellogenic (postvitellogenic), germinal vesicle break down and spawning stage [39]. In ovary, there is coordinated activities for various regulators of ovulation like proteases, protease inhibitors, progestational steroids, eicosanoids, catecholamines and vasoactive peptides [ 40 .

Thus, we can see that neuroendocrine control of BPGL axis and its associated gene regulatory network operating in brain, pituitary, gonad and liver are well coordinated to manifest seasonality in fish breeding by sensing photoperiod using biological clock genes along with temperature and food abundance [3]. We observed LH controlled DEG (poliovirus receptor and Bloodthirsty) involved in gonad development and maturation associated genes (ehmt2 and racgap1) which is also reported in rainbow trout. FSH modulates steroidogenic pathway as well as early germ cell proliferation and differentiation. We found four major pathways and their genes which are differentially expressed in BPGL axis viz., IGF pathway (insulin gene enhancer protein, insulin receptor, insulin-induced gene, precursor of insulin and its receptor), the TGF pathway ( $a m h$, inha and fst/3), the Wnt pathway (wisp 1), and pleiotrophin ( $m d k a)$ which are also reported in rainbow trout [3]. Insulin gene enhancer protein isl with its 3 isoforms families (Isl-1,2,3), observed in our dataset which is reported to play role in regulation of IGF pathway [41]. SV organ acts as a sensor of seasonality by sensing the day length/photoperiod by rhodopsin molecule. Thus, rhodopsin gene family must be one of the major hub in brain tissue acting as a transducer for neuroendocrine output in form of GnRH [28].

\section{GRN in Liver controlling seasonality}

GRN in liver controlling seasonality was constructed using top 100 co-expressed genes to depict proteinprotein interactive network. Genes were selected at a cut off degree 165. A total of 25 hub genes were predicted having 9 up, 16 down regulated genes shown in Supplementary file 10. JAK/STAT signaling pathway was found to control glycolysis, gluconeogenesis, oxidative phosphorhylation, apolipo protein production, $\mathrm{MHC}$ response, retenoic acid, betain and GABA, immune response, cholesterol and lipid transport (Table 9). Like all oviparous vertebrates, in fish also, egg-yolk and chorionic proteins like vitellogenin and choriogenin are synthesized heterologously in the liver [42]. Fish liver is also involved in synthesis, degradation, transportation, and storage of lipid. These major activities are well coordinated by BPGL axis along with oocyte growth and development in tune of seasonality. The axis synchronises the food availability and ingestion behaviour along with photoperiod, temperature and gonadal maturation leading to seasonal reproduction in temperate fishes [43]. In vitellogenesis period, there is increase in GSI 
and HSI due to increase in total protein, glycogen and cholesterol content of the ovary and liver and stored fat reserve is used for gonadal maturation [44].

We also found upregulation of Wht and Notch signaling genes in all the four tissues of BPGL axis having multifarious role including higher perceptivity of auditory system in breeding season. This is in response to estrogen induced seasonal changes [45]. Besides tissue specific GRN, there are some common set of genes which are expressed in different magnitudes in different tissue with respect to seasonality. Expression of plectin gene was found to be most abundant in liver and gonads rather than brain and pituitary. Plectin proteins are abundant $(75 \%)$ in cytoskeleton of ovary, which is a major phosphoacceptor, in phosphorylation, thus important for the protein's association with the cytoskeleton [46]. Plectin is a hemidesmosomal protein that mediates hyperproliferation of gonads and liver. It also increases the expression of estrogen receptor in fish gonads which triggers seasonal response in ovary manifesting seasonality [47]. Claudin gene was found to be upregulated in all the 4 tissues but its highest expression was found in gonads. Claudin in teleost fish is reported to be tissue specific in expression. It functions as pore forming TJ protein increasing luminal fluid accumulation and volume expansion in ovary [48] as observed in histological picture (Figure 1).

\section{qPCR for validation of DEG}

To validate the finding, qPCR analysis was performed. Relative gene expression of randomly selected 20 differentially expressed genes along with one housekeeping gene (beta actin) showed similar magnitude with the computed log fold change value except three genes (Supplementary file 11). This could be due to cross-reactivity in the designed primer [49].

\section{Discovery and role of biological clock genes in carp fish for circannual breeding}

Blast hit of four sets of DEGs revealed presence of at least 32 well known biological genes in carp fish. These sets of transcripts represent carp fish specific BCG sequences which is also a direct evidence for presence of these biological clock genes in this fish. These differentially expressed BCGs in BPGL tissues are involved in manifestation of circannual rhythm of breeding. In case of European fish reproductive axis gene expression in brain is known to be modulated by photoperiod which is regulated by biological clock genes and conserved transcription factors [3].

This is the first report having transcriptomic evidence of biological clock genes in rohu mediating seasonality over BPGL axis controlling reproductive behaviour. Interestingly, all these 32 biological clock genes are well conserved from lower vertebrate like cyclostome (Lamprey) to higher vertebrate like mammals. In pituitary, we found differential expression of Bmal1, Clock, Per1, Per2, Cry1 and Cry2 genes sensing duration of photoperiod for synchronization in BPGL axis. This culminates in manifestation of reproductive seasonality with circannual rhythm [50].

Few already reported genes of rohu fish involved in seasonality regulation were also found in our dataset. For example Kisspeptin and its receptor Kissr [51]. We found differential expression of known sex 
determining and seasonality genes for example aromatase cyp19a1a, estrogen receptor esr1a, and foxl2 in ovaries similar to Iberian cyprinid fish (Squalius pyrenaicus) [52] and GnRH3, similar to other teleost [53]. Similar gene family like Kiss and gnrh are reported to control reproductive axis under influence of contrasting day length as photoperiod in fish sea bass [54].

Though expression of biological clock genes are tissue specific as well as magnitude specific [55] but they are well coordinated and synchronized across various organs involved in sensing photoperiod, ambient temperature, food supplies, immunity, locomotory activity and body growth [56] enabling the fish for seasonal breeding. Isotocin-neurophysin gene was found to be upregulated in brain. Isotocin is teleost homologue of mammalian oxytocin. In case of zebra fish it has been reported that isotocin stimulates the proliferation of cells enhancing the functional activities of ionocytes. Isotocin stimulates the proliferation of cells in fish gonads [57]. Similarly, higher expression of synaptotagmin gene was also found in hypothalamus and pituitary which is involved in neurotransmitter secretion [58].

Reproductive seasonality in fish is reported to be controlled by hypothalamus/ SV organ which acts as a sensor of seasonal changes in day length [28]. Existence of this organ is already reported in Labeo rohita [59]. Present transcriptome based study in rohu also confirms the seasonality control by similar regulatory pathway of BPGL axis. Seasonality in tropical fishes is an adaptation to environment and its optimal growth and perpetuation of species in its specific ecological niches. Fish represents vertebrate circadian timing system operated by circadian biological clock and photoreceptor organ. This ability originates during embryogenesis and continues till reproductive age [60]. Seasonal reproductive behaviour is induced by environmental cues. Various sets of biological clock sense the environmental cues and acts as a transducer eliciting neuroendocrine mediated developmental and physiological events under coordination of BPGL axis [61].

\section{Evolutionary conservation of BCGs from cyclostome to eutherian mammals}

Extent of conservation in primitive jawless fish like lamprey, cartilaginous, teleost, lung fish; amphibian, bird, reptile and three mammalian classes (monotreme, marsupials and eutherians) is summarized in table 10. The comparative analysis of carp fish BCGs sequence with different vertebrate phyla indicates that these biological clock genes are well conserved in all. Maximum percentage similarity of all the 32 biological clock genes of rohu was found with jawless fish, lamprey. However, query coverage was maximum up to $100 \%$ with cyprinid (common carp) and zebrafish up to $100 \%$ (Supplementary file 12). Circular plot shows further qualitative depiction of extent of conservation in selected six phyla namely, amphibian, fish, birds reptiles, eutherian mammals and ovoviviparous mammals (figure 5). These findings infer that genes and neuroendocrine pathways sensing environmental cues are well conserved during evolutionary process of species diversification into different classes of vertebrates [62]. Such biological clock genes are reported to be conserved in other fishes also like Atlantic cod fish having 18 conserved biological clock genes [63]. Thus, investigation of present transcriptomic landscape revealed that at least 32 reported biological clock genes of other diverse species are also present in rohu fish. With seasonal changes these genes are differentially expressed synchronizing environment and reproduction. 
In evolution, biological clock has been found universal, which originated 2.5 billion years ago [64]. This is because of universality in response of all evolving organisms against change in day length with rotation of earth having daily and seasonal variation in environment. Environmental signal entrains the BCGs to trigger seasonal behaviour for annual biological rhythm for reproduction/migration [65]. Magnitude of biological rhythm varies from 20 minutes (bacterial reproduction) to daily as circadian rhythm but such rhythm may have much longer duration like tidal rhythm (14 days), lunar rhythm ( 28 days), circannual rhythm one year, sometime it may be of 17 years (cicada species emergence from ground) to 60 years (bamboo flowering) [66].

Circadian rhythm is well connected to lunar, tidal, circannual rhythm in hibernating mammals. It is also present in invertebrates [67]. Circannual rhythm of breeding is well known in farm fishes, birds and mammals [68]. These finding re-endorses that there is a universal mechanism at molecular level regulating seasonal reproduction in vertebrates right from fish to mammal which starts from photo period sensing by retina and signals to neurohypophyseal complex for endocrinal output in a fish-specific organ called saccus vasculosus [69]. Artificial manipulation of day length affects rhythmicity of biological clock affecting reproductive activities like ovulation, spermatogenic activity, gamete quality and sexual behaviour in fish, bird and mammals [68]. Oscillation in biological rhythm has adaptive significance to reduce competition between species by occupying differential species specific spatial niches. This is done by differential phasing of biological rhythm which is entrained by both internal and external force [8]. Thus we observe ubiquity of circadian rhythm phylogenetically having strong adaptive significance [70]. This evolutionary comparative genomic study endorses that fish biological clock can be used as a model for research and knowledge discovery in terms of depicting molecular and cellular mechanism in response to environment in applied research like drug efficacy for jetlag etc [71].

\section{Web genomic resources of evolutionary conserved BCGs and candidate genes of seasonality}

Present investigation of environmentally triggered reproduction can be of much relevance in the endeavour of out of seasonal breeding leading to higher fish productivity [56]. The present genomic resource catalogues 75554 differentially expressed transcripts, 115534 SSRs, 65584 SNPs from de novo assembly, 514 pathways, 5379 TFs, 187 mature miRNA regulating 1576 DEGs and 32 BCGs. It also catalogues ready to use primers. This is freely accessibility for academic purpose.

Fish transcriptome can be a powerful tool to establish relationship between genotype and phenotype using structural and functional annotation approach [72]. In rohu fish, SSRs and SNPs have been reported to be associated with important disease resistant trait against aeromoniasis bacterial disease [72]. Our transcriptome database can be used as genomic resources as it is having putative markers useful for similar association studies in future [73]. Such genomic resources having SNP markers has also been used in linkage mapping and QTL discovery in rohu fish [74].

Candidate genes involved in GRN of ovary can be used in SNP discovery and future association studies in fish selection. Liver GRN genes can be used for biomonitoring of fish breeding area with seasonality to predict magnitude of fish productivity [75]. GRN of liver having TOR signaling pathway which is 
associated with lipogenesis can be over-activated to utilize glucose more efficiently by genetic selection [76]. Similarly genes expressed in liver associated with innate immune system can be used for biomonitoring of fish mortality [77].

\section{Conclusion}

This is the first report in carp fish rohu deciphering candidate genes of circannual biological rhythm of reproduction along with BCGs. Study reveals reproductive seasonality of rohu fish with elucidation of neuroendocrine physiological events at molecular level. We present the transcriptomic landscape of BPGL axis operating through various gene regulatory network associated with tissue involved in manifestation of circannual breeding having environmental synchronization by BCGs and BPGL axis. Differentially expressed genes in BPGL tissues along with putative molecular markers (SSRs and SNPs), pathways, transcription factors, mature miRNA and BCGs are available in the form of web genomic resources (LrSATDb: http://webtom.cabgrid.res.in/Irsatdb/). This study reveals atleast 32 BCGs in this carp fish for the first time which are also highly conserved across jawless, cartilaginous, teleost fish, amphibian, reptile, birds, prototheria, marsupials and placental mammals. This is because of universal molecular mechanism of rhythmicity in response to environment and earth rotation. Biological rhythm and its amplitude has different adaptive and reproductive significance during speciation and evolutionary divergence of different taxa.

Gene regulatory network operating in BPGL tissues mediating photo-periodism sensing, neuroendocrine secretion, metabolism and yolk synthesis in liver, gonadal maturation, muscular growth with sensory and auditory perception in this fish are elucidated. Study further reveals that fish can be a good model for research on biological clock besides its immense use in the endeavour of reproductive efficiency improvement.

\section{Methods}

\section{Ethics Statement}

This study was approved by the Animal Ethics Committee of ICAR-CIFA, Bhubaneswar. All the fishes (rohu, Labeo rohita) used in the experiments were handled according to the prescribed guidelines of the Institute.

\section{Tissue sample collection}

Brain, pituitary, gonad (ovary) and liver tissues of adult rohu female were collected during resting PSR phase (in December) and IGA phase (in February), respectively. The fishes were euthanized with MS-222 at $300 \mathrm{mg} / \mathrm{L}$ before dissection. Tissues were collected from minimum ten fishes for each phase, quickly frozen in liquid nitrogen and stored at $-80^{\circ} \mathrm{C}$, until used for RNA extraction. Carp fish, brood stock was reared in ICAR-CIFA farm ponds (Latitude $20^{\circ} 1^{\prime} 06^{\prime \prime}-20^{\circ} 11^{\prime} 45^{\prime \prime} \mathrm{N}$, Longitude $80^{\circ} 50^{\prime} 52^{\prime \prime}-85^{\circ} 51^{\prime} 35^{\prime \prime} \mathrm{E}, 45 \mathrm{~m}$ $\mathrm{MSL}$ ). For optimal growth maintenance, stocking density was maintained at the rate of $1500 \mathrm{~kg} / \mathrm{ha}$ along 
with routine monitoring of water temperature, $\mathrm{pH}$, dissolved oxygen, total alkalinity and total hardness at $28-30^{\circ} \mathrm{C}, 7.5-8.5,100-140 \mathrm{ppm}$, and 100-130 ppm, respectively.

\section{Reproductive phase identification by estimation of GSI and histology}

The gonado somatic index (GSI) and histological analysis of gonads were carried out to confirm the reproductive phases. For GSI and histological observation, fishes were humanely sacrificed. GSI was calculated using the formula: GSI=Gonad weight/ Total tissue weight x100 [78]. For histology, middle portion of the right and left lobes of the gonads from the sampled fish were taken after dissection. The gonad samples (1-1.5mm thickness) were immersed in Bouin's fixative for 24 hour and $5 \mu \mathrm{m}$ thick sections were cut using a mechanical microtome (WESWOX Optik Rotary Microtome, Ambala Cantt, India) and stained using haematoxylin and eosin. Gonads were processed for examination with light microscopy using routine histological procedures [79].

\section{RNA extraction and sequencing}

Total RNA was extracted using Qiagen RNeasy mini kit using manufacturer's protocol. RNA concentration and purity were estimated using Bioanalyzer 2100 (Agilent, Santa Clara, CA, USA) and samples having RIN (RNA Integrity Number) $>7.0$ were used for sequence data generation. Library preparation was performed using Illumina TruSeq RNA library protocol and sequenced on Illumina HiSeq 2000 platform (Illumina, San Diego, CA) to generate 100 nucleotide pair-end reads.

\section{Pre-processing, de-novo assembly, abundance estimation and annotation}

The paired end reads generated from Illumina for PSR and IGA phases from BPGL tissues were taken for the study. Data were pre-processed for quality check and low quality reads, reads with ambiguous bases ' $\mathrm{N}$ ' and adaptor sequences were trimmed using FASTQC [80] and trimmomatic [81] tool. The processed tissues specific paired end reads of PSR and IGA phases were pooled together and de novo assembly with default parameters were performed using Trinity [82]. Further, abundance estimation was performed using RSEM (RNA-Seq by Expectation Maximization) [83] and DEGs were identified from the data set under study. DEGs from comparative studies of IGA season vs. PSR season were identified in each of the BPGL tissues using edgeR package [84].

\section{Homology search and functional characterization of candidate genes}

Standalone NCBI blast package was used for sequence similarity search of all novel transcripts and differential expressed genes against the NCBI non-redundant database (nr.32). Annotation was done for the DEGs along with functional categorization, interproscan, mapping and identification of KEGG pathways using Blast2GO PRO 3.1 software [10]. Danio rerio transcription factors from AnimalTFDB 2.0 database [11] were retrieved to predict similar transcription factors for differential expressed genes of BPGL tissues in rohu. 
Simple Sequence Repeats (SSRs) were detected from L. rohita by using MISA perl script [85]. Mononucleotides, dinucleotides, trinucleotides, tetranucleotides, pentanucleotides and hexanucleotides repeating units were identified with default parameters i.e. 10 repeating units for mono-, 6 repeating units for di-, 5 for tri-, tetra-, penta- and hexa-nucleotides.

SNPs and Indels were detected using two references i.e. Danio rerio reference genome data and generated de novo transcription reference assembly. The reference genome of Danio rerio GRCz10 was retrieved from ensemble database (http://asia.ensembl.org/Danio_rerio/Info/Index?redirect=no) as it is closely related species of $L$. rohita and both belongs to same family, Cyprinidae. We separately identified the SNPs and Indels from IGA and PSR tissue samples. Burrows-Wheeler Aligner (BWA) tool [86] was used to alignment and SAMtools package used for calling SNPs and Indels [87]. Annotation of SNPs and Indels were performed using SnpEff tool (http://snpeff.sourceforge.net/).

\section{miRNA target prediction of DEGs}

A total of 1637 mature miRNA sequences of nine fish species such as Danio rerio, Fugu rubripes, Cyprinus carpio, Hippoglossus hippoglossus, Ictalurus punctatus, Oryzias latipes, Paralichthys olivaceus, Salmo salar and Tetraodon nigroviridis were retrieved from miRBase database release 21 [88]. MiRNA target predictions of $L$. rohita from DEGs of all stages were performed by using miRanda-3.3a tool [89].

\section{Construction of Gene Regulatory Network}

Gene regulatory network (GRN) was constructed using up and down regulated DEGs having $>8$ fold difference in expression. Visualization was done using open source tool, Cytoscape version 3.2.1 [90]. Network centrality was analysed using Network Analyzer plug-in. Analysis of degree, betweenness and stress were used to identify hub genes and its network. The "logical model" was constructed based on sample size [25].

\section{qPCR for validation of DEG}

For quantitative PCR, 20 transcripts were randomly selected. Primers were designed using Primer 3 software [91]. The primer were synthesised in 10nm scale and purified by HPLC. The total RNA were converted into cDNA using affinity script qPCR cDNA synthesis kit (Agilent Technologies, USA) as per manufacturer's protocol. Gene expressions were measured using SYBR Green chemistry (Brilliant II SYBR Green qPCR master mix, Agilent Technologies, USA) with standard 40 cycles in Stratagene mx3005P instrument (Agilent Technologies, USA). The dissociation curve analysis was performed to ensure specificity of amplification. The mean Ct value of technical replicates were calculated. Magnitude of differential gene expression were calculated in terms of $\Delta \Delta C T$ fold change value as described by Pfaffl [92]. Housekeeping beta actin gene was used as reference to normalize the qPCR data. Fold change values were computed by log transformation (Log2). 
Four sets of DEG obtained from BPGL tissue were subjected to homology search using BLAST. From literature, names of known BCGs $[50,79,63]$ were used to identify carp fish specific BCG transcripts as an evidence of BCGs. These selected BCG transcripts were used for further analysis (supplementary file 12).

\section{Evolutionary conservation of BCGs from cyclostome to eutherian mammals}

To identify biological clock genes and their extent of conservation, comparative genomics approach was used. For this study, 32 genes were selected viz. Bmal2,clock, cry1,cry2, foxl2, GNRH, kisspeptin, LH (Luteinizing hormone), Per1, Per2, Per3, esr1a, PVR, Bty, wisp1, mdka, amh, ependymin, CaMK2, ehmt1, ehmt2, racgap1, fst/3, fst/4, fst/5, prdm, Otx, Myc, srebf1, pac, picalm and aanat and homology search was done using Blastn programme of NCBI of 10 different genomes representing various classes of chordates such as jawless fish Petromyzon marinus (GCA_000148955.1); cartilaginous fish whale shark Rhincodon typus (GCA_001642345.2); teleost Danio rerio (GCA_000002035.4); Common carp Cyprinus carpio (GCA_000951615.2); Amphibia tropical clawed frog Xenopus tropicalis (GCA_000004195.3); Bird Gallus gallus (GCA_000002315.3); reptile Green anole Anolis carolinensis (GCA_000090745.2); egg laying mammal Ornithorhynchus anatinus (GCF_000002275.2), ovoviviparous mammal Monodelphis domestica (GCF_000002295.2), eutherian mammals Ovis aries (sheep) (GCA_000298735.2).

Web genomic resources of evolutionary conserved BCGs and candidate genes of seasonality

An online relational database of rohu fish transcriptome was developed which catalogues tissue wise transcripts/contigs, putative SSRs, SNPs, Indels, transcription factors, miRNA targets representing two reproductive phases (IGA and PSR). The architecture is "three-tier architecture" viz., client-, middle- and database tier. This genomic resource is freely accessible for non-commercial use at http://webtom.cabgrid.res.in//rsatdb/. In order to browse and query, user can go through the web pages in client tier. All the information are available in various tables corresponding to MySQL in the database tier. Server side scripting in PHP was done in the middle tier for database connectivity, query execution and fetching. In order to generate primers over selected markers, Primer3 executable was integrated at the backend.

\section{Abbreviations}

BCGs: Biological clock genes

BPGL: Brain-Pituitary-Gonad-Liver

QPCR:Quantitative polymerase chain reaction

GRN: Gene regulatory networks

EST: Expressed sequence tag

SSR: Simple sequence repeats 
SNP: Single nucleotide polymorphism

DEG: Differentially expressed genes

PSR: Post-spawning regression

IGA: Initiation of gonadal activity

POF: Primary ovarian follicles

SOF: Secondary ovarian follicles

BR: Brain

PIT: Pituitary

LIV: Liver

OVA: Ovary

KEGG: Kyoto Encyclopedia of Genes and Genomes

TF: Transcription factors

Blast: Basic local alignment search tool

\section{Declarations}

\section{Competing interest}

The authors declare that they have no competing interests.

\section{Funding}

This work was supported by ICAR-CIFA, Bhubaneshwar (Institute Project Code: I-59(n), P1-2012/2-FA-L10/8110) and CABin grant of ICAR-IASRI (F. no. Agril. Edn.4-1/2013-A\&P). Authors are thankful to Director, ICAR-CIFA, Bhubaneshwar for sanctioning the project to SN as Principal Investigator for all financial support in genomic data generation.

\section{Ethics Statement}

This study was approved by the Animal Ethics Committee of ICAR-CIFA, Bhubaneswar. All the fishes (rohu, Labeo rohita) used in the experiments were handled according to the prescribed guidelines of the Institute.

\section{Availability of Supporting Data}


The transcriptome dataset of the study used in this article are available in the NCBI repository with following accessions and is kept at hold till the publication. These would be made public after publication. (Bioproject: PRJNA401304; BioSamples: SAMN07602341, SAMN07602342, SAMN07602343, SAMN07602344, SAMN07602345, SAMN07602346, SAMN07602347, SAMN07602348).

\section{Acknowledgement}

This work was supported by ICAR-CIFA, Bhubaneshwar (Institute Project Code: I-59(n), P1-2012/2-FA-L10/8110) and CABin grant of ICAR-IASRI (F. no. Agril. Edn.4-1/2013-A\&P). Authors are thankful to Director, ICAR-CIFA, Bhubaneshwar for sanctioning the project to SN as Principal Investigator for all financial support in genomic data generation. Authors are also thankful to Indian Council of Agricultural Research, Ministry of Agriculture and Farmers' Welfare, Govt. of India for providing financial assistance in the form of CABin grant as well as Advanced Super Computing Hub for Omics Knowledge in Agriculture (ASHOKA) facility at ICAR-IASRI, New Delhi, India created under National Agricultural Innovation Project, funded by World Bank.

\section{Author Contributions}

SN, DK and JKS conceived theme of the study. SN designed the experiment and generated the genomic data along with SP, GM, UKU, DKS, PKM, DKV, PR and PD. SJ, MAI, RSJ and UBA did computational analysis and developed genomic resource. SJ, MAI, RSJ, DK and SN drafted the manuscript. SN, JKS, PJ, DK and AR edited the manuscript. All co-authors read and approved the final manuscript.

\section{References}

1. Jhingran VG: Fish and fisheries of India. 1975, 1-954.

2. Mistlberger RE, Antle MC: Entrainment of circadian clocks in mammals by arousal and food. Essays in biochemistry. 2011, 49:119-36.

3. Martins RS, Gomez A, Zanuy S, Carrillo M, Canário AV: Photoperiodic modulation of circadian clock and reproductive axis gene expression in the pre-pubertal European sea bass brain. PloS one. 2015, 10(12):e0144158.

4. Kullgren A, Jutfelt F, Fontanillas R, Sundell K, Samuelsson L, Wiklander K, Kling P, Koppe W, Larsson DJ, Björnsson BT, et al: The impact of temperature on the metabolome and endocrine metabolic signals in Atlantic salmon (Salmo salar). Comparative Biochemistry and Physiology Part A: Molecular \& Integrative Physiology. 2013, 164(1):44-53.

5. Isorna E, De Pedro N, Valenciano Al, Alonso-Gómez ÁL, Delgado MJ: Interplay between the endocrine and circadian systems in fishes. Journal of Endocrinology. 2017, 232(3):R141-59.

6. Sahu DK, Panda SP, Panda S, Das P, Meher PK, Hazra RK, Peatman E, Liu ZJ, Eknath AE, Nandi S: Identification of reproduction-related genes and SSR-markers through expressed sequence tags analysis of a monsoon breeding carp rohu, Labeo rohita (Hamilton). Gene. 2013, 524(1):1-4. 
7. Sahu DK, Panda SP, Meher PK, Das P, Routray P, Sundaray JK, Jayasankar P, Nandi S: Construction, de-novo assembly and analysis of transcriptome for identification of reproduction-related genes and pathways from rohu, Labeo rohita (Hamilton). PloS one. 2015, 10(7):e0132450.

8. Menaker M. Biological clocks. Bioscience. 1969;19 (8):681-92.

9. Sundararaj BI, Vasal S: Photoperiod and temperature control in the regulation of reproduction in the female catfish Heteropneustes fossilis. Journal of the Fisheries Board of Canada. 1976, 33(4):959973.

10. Conesa A, Götz S, García-Gómez JM, Terol J, Talón M, Robles M: Blast2GO: a universal tool for annotation, visualization and analysis in functional genomics research. Bioinformatics. 2005, 21(18):3674-3676.

11. Zhang HM, Liu T, Liu CJ, Song S, Zhang X, Liu W, Jia H, Xue Y, Guo AY: AnimalTFDB 2.0: a resource for expression, prediction and functional study of animal transcription factors. Nucleic acids research. 2014, 43(D1):D76-D81.

12. Ishida N, Kaneko M, Allada R: Biological clocks. Proc Natl Acad Sci USA. 2000, 97(16): 9347.

13. Ma H, Weber GM, Hostuttler MA, Wei H, Wang L, Yao J: MicroRNA expression profiles from eggs of different qualities associated with post-ovulatory ageing in rainbow trout (Oncorhynchus mykiss). BMC genomics. 2015, 16(1):201.

14. Ramachandra RK, Salem M, Gahr S, Rexroad CE, Yao J: Cloning and characterization of microRNAs from rainbow trout (Oncorhynchus mykiss): their expression during early embryonic development. BMC developmental biology. 2008, 8(1):41.

15. Soni K, Choudhary A, Patowary A, Singh AR, Bhatia S, Sivasubbu S, Chandrasekaran S, Pillai B: miR34 is maternally inherited in Drosophila melanogaster and Danio rerio. Nucleic acids research. 2013, 41(8):4470-4480.

16. Juanchich A, Le Cam A, Montfort J, Guiguen Y, Bobe J: Identification of differentially expressed miRNAs and their potential targets during fish ovarian development. Biology of reproduction. 2013, 88(5):128-131.

17. Presslauer C, Bizuayehu TT, Kopp M, Fernandes JM, Babiak I: Dynamics of miRNA transcriptome during gonadal development of zebrafish. Scientific reports. 2017, 7:43850.

18. Uitdewilligen JG, Wolters AM, Bjorn B, Borm TJ, Visser RG, van Eck HJ: A next-generation sequencing method for genotyping-by-sequencing of highly heterozygous autotetraploid potato. PloS one. 2013, 8(5):e62355.

19. Hur B, Chae H, Kim S: Combined analysis of gene regulatory network and SNV information enhances identification of potential gene markers in mouse knockout studies with small number of samples. BMC medical genomics. 2015, 8(2):S10.

20. Kim DC, Wang J, Liu C, Gao J: Inference of SNP-Gene Regulatory Networks by Integrating Gene Expressions and Genetic Perturbations. BioMed Research International. 2014, 629697.

21. Karlebach G, Shamir R: Modelling and analysis of gene regulatory networks. Nature Reviews Molecular Cell Biology. 2008, 9(10):770-780. 
22. Zhu J, Alvarez S, Marsh EL, LeNoble ME, Cho IJ, Sivaguru M, Chen S, Nguyen HT, Wu Y, Schachtman DP, et al: Cell wall proteome in the maize primary root elongation zone. II. Region-specific changes in water soluble and lightly ionically bound proteins under water deficit. Plant Physiology. 2007, 145(4):1533-1548.

23. Narang V, Ramli MA, Singhal A, Kumar P, de Libero G, Poidinger M, Monterola C: Automated identification of core regulatory genes in human gene regulatory networks. PLoS computational biology. 2015, 11(9):e1004504.

24. Cai X, Bazerque JA, Giannakis GB: Inference of gene regulatory networks with sparse structural equation models exploiting genetic perturbations. PLoS computational biology. 2013, 9(5):e1003068.

25. Vijesh N, Chakrabarti SK, Sreekumar J: Modeling of gene regulatory networks: A review. Journal of Biomedical Science and Engineering. 2013, 6(02):223.

26. Taranger GL, Carrillo M, Schulz RW, Fontaine P, Zanuy S, Felip A, Weltzien FA, Dufour S, Karlsen $\emptyset$, Norberg B, et al: Control of puberty in farmed fish. General and comparative endocrinology. 2010, 165(3):483-515.

27. Matsui H: Dopamine system, cerebellum, and nucleus ruber in fish and mammals. Development, growth \& differentiation. 2017, 59:219-227.

28. Nakane Y, Ikegami K, ligo M, Ono H, Takeda K, Takahashi D, Uesaka M, Kimijima M, Hashimoto R, Arai N, et al: The saccus vasculosus of fish is a sensor of seasonal changes in day length. Nature communications. 2013, 4:2108.

29. Dardente H, Hazlerigg DG, Ebling FJ: Thyroid hormone and seasonal rhythmicity. Frontiers in endocrinology. 2014, 5:19.

30. Danzmann RG, Kocmarek AL, Norman JD, Rexroad CE, Palti Y: Transcriptome profiling in fast versus slow-growing rainbow trout across seasonal gradients. BMC genomics. 2016, 17(1):60.

31. Basinou V, Park JS, Cederroth CR, Canlon B: Circadian regulation of auditory function. Hearing research. 2017, 347:47-55.

32. Margolis-Kazan H, Schreibman MP: Cross-reactivity between human and fish pituitary hormones as demonstrated by immunocytochemistry. Cell and tissue research. 1981, 221(2):257-67.

33. Trudeau VL: Neuroendocrine regulation of gonadotrophin II release and gonadal growth in the goldfish, Carassius auratus. Reviews of reproduction. 1997, 2(1):55-68.

34. Habibi HR, De Leeuw R, Nahorniak CS, Goos HT, Peter RE: Pituitary gonadotropin-releasing hormone $(\mathrm{GnRH})$ receptor activity in goldfish and catfish: seasonal and gonadal effects. Fish physiology and biochemistry. 1989, 7(1-6):109-118.

35. Melamed P, Rosenfeld H, Elizur A, Yaron Z: Endocrine regulation of gonadotropin and growth hormone gene transcription in fish. Comparative Biochemistry and Physiology Part C: Pharmacology, Toxicology and Endocrinology. 1998, 119(3):325-38.

36. Sambroni E, Lareyre JJ, Le Gac F: Fsh controls gene expression in fish both independently of and through steroid mediation. PLoS One. 2013, 8(10):e76684. 
37. Guzmán JM, Luckenbach JA, Yamamoto Y, Swanson P: Expression profiles of Fsh-regulated ovarian genes during oogenesis in coho salmon. PloS one. 2014, 9(12):e114176.

38. Prasad P, Ogawa S, Parhar IS: Role of serotonin in fish reproduction. Frontiers in neuroscience. 2015, 9:195.

39. Sen U, Mukherjee D, Bhattacharyya SP, Mukherjee D: Seasonal changes in plasma steroid levels in Indian major carp Labeo rohita: influence of homologous pituitary extract on steroid production and development of oocyte maturational competence. General and comparative endocrinology. 2002, 128(2):123-34.

40. Goetz FW, Garczynski M: The ovarian regulation of ovulation in teleost fish. Fish Physiology and Biochemistry. 1997, 17(1-6):33-38.

41. Hemati N, Ross SE, Erickson RL, Groblewski GE, MacDougald OA: Signaling pathways through which insulin regulates CCAAT/enhancer binding protein a (C/EBPa) phosphorylation and gene expression in 3T3-L1 adipocytes correlation with GLUT4 gene Expression. Journal of Biological Chemistry. 1997, 272(41):25913-25919.

42. Arukwe A, Goksøyr A: Eggshell and egg yolk proteins in fish: hepatic proteins for the next generation: oogenetic, population, and evolutionary implications of endocrine disruption. Comparative hepatology. 2003, 2(1):4.

43. Ballesteros TM, Torres-Mejia M, Ramírez-Pinilla MP: How does diet influence the reproductive seasonality of tropical freshwater fish?: A case study of a characin in a tropical mountain river. Neotropical ichthyology. 2009, 7(4):693-700.

44. Shaikh Abdullah S, Lohar PS: Biochemical composition and gonadosomatic index of three major carps in Hatnoor reservoir, Maharashtra, India. Journal of Ecobiotechnology. 2011, 3(6):1-4.

45. Faber-Hammond J, Samanta MP, Whitchurch EA, Manning D, Sisneros JA, Coffin AB: Saccular Transcriptome Profiles of the Seasonal Breeding Plainfin Midshipman Fish (Porichthys notatus), a Teleost with Divergent Sexual Phenotypes. PloS one. 2015, 10(11):e0142814.

46. Herrmann $\mathrm{H}$, Wiche G: Specific in situ phosphorylation of plectin in detergent-resistant cytoskeletons from cultured Chinese hamster ovary cells. Journal of Biological Chemistry. 1983, 258(23):1461014618.

47. Wada-Hiraike $O$, Imamov O, Hiraike H, Hultenby K, Schwend T, Omoto Y, Warner M, Gustafsson JÅ: Role of estrogen receptor $\beta$ in colonic epithelium. Proceedings of the National Academy of Sciences of the United States of America. 2006, 103(8):2959-2964.

48. Kolosov D, Bui P, Chasiotis H, Kelly SP: Claudins in teleost fishes. Tissue barriers. 2013, 1(3):e25391.

49. Spandidos A, Wang $X$, Wang $H$, Dragnev $S$, Thurber $T$, Seed B: A comprehensive collection of experimentally validated primers for Polymerase Chain Reaction quantitation of murine transcript abundance. BMC genomics. 2008, 9(1):633.

50. Lincoln GA, Andersson H, Loudon A: Clock genes in calendar cells as the basis of annual timekeeping in mammals-a unifying hypothesis. Journal of Endocrinology. 2003, 179(1):1-13. 
51. Chi L, Li X, Liu Q, Liu Y: Photoperiod regulate gonad development via kisspeptin/kissr in hypothalamus and saccus vasculosus of Atlantic salmon (Salmo salar). PloS one. 2017, 12(2):e0169569.

52. Machado MP, Matos I, Grosso AR, Schartl M, Coelho MM: Non-canonical expression patterns and evolutionary rates of sex-biased genes in a seasonal fish. Molecular reproduction and development. 2016, 83(12):1102-15.

53. Bar I, Cummins S, Elizur A: Transcriptome analysis reveals differentially expressed genes associated with germ cell and gonad development in the Southern bluefin tuna (Thunnus maccoyii). BMC genomics. 2016, 17(1):217.

54. Espigares F, Rocha A, Gómez A, Carrillo M, Zanuy S: Photoperiod modulates the reproductive axis of European sea bass through regulation of kiss1 and gnrh2 neuronal expression. General and comparative endocrinology. 2017, 240:35-45.

55. Ko CH, Takahashi JS: Molecular components of the mammalian circadian clock. Human molecular genetics. 2006, 15(2):R271-7.

56. Bowden TJ, Thompson KD, Morgan AL, Gratacap RM, Nikoskelainen S: Seasonal variation and the immune response: a fish perspective. Fish \& shellfish immunology. 2007, 22(6):695-706.

57. Chou MY, Hung JC, Wu LC, Hwang SP, Hwang PP: Isotocin controls ion regulation through regulating ionocyte progenitor differentiation and proliferation. Cellular and Molecular Life Sciences. 2011, 68(16):2797-809.

58. Xi D, Chi H, Gainer H: Analysis of synaptotagmin I-IV messenger RNA expression and developmental regulation in the rat hypothalamus and pituitary. Neuroscience. 1999, 88(2):425-35.

59. Rao PP: Studies on the structural variations in the brain of teleosts and their significance. Cells Tissues Organs. 1967, 68(3):379-99.

60. Vatine G, Vallone D, Gothilf Y, Foulkes NS: It's time to swim! Zebrafish and the circadian clock. Febs Letters. 2011, 585(10):1485-94.

61. Paibomesai MI, Moghadam HK, Ferguson MM, Danzmann RG: Clock genes and their genomic distributions in three species of salmonid fishes: Associations with genes regulating sexual maturation and cell cycling. BMC research notes. 2010, 3(1):215.

62. Reaume CJ, Sokolowski MB: Conservation of gene function in behaviour. Philosophical Transactions of the Royal Society B: Biological Sciences. 2011, 366(1574):2100-10.

63. Lazado CC, Kumaratunga HP, Nagasawa K, Babiak I, Giannetto A, Fernandes JM: Daily rhythmicity of clock gene transcripts in Atlantic cod fast skeletal muscle. PLoS One. 2014, 9(6):e99172.

64. Callaway E. 2012. A biological clock to wind them all. Nature News. (Nature Publishing Group).

65. Kumar V, Wingfield JC, Dawson A, Ramenofsky M, Rani S, Bartell P: Biological clocks and regulation of seasonal reproduction and migration in birds. Physiological and Biochemical Zoology. 2010, 83(5):827-35.

66. Williams Sarah CP: Hacking the biological clock. Life Time. 2015, Stanford Medicine. 
67. Mary AB: Circannual Rhythmicity in Invertebrates In Circannual Clocks: Annual Biological Rhythms Ed Pengelley E T, 1974, Pages 11-53, Academic Press

68. Chemineau P, Malpaux B, Brillard JP, Fostier A: Seasonality of reproduction and production in farm fishes, birds and mammals. Animal. 2007, 1(3):419-32.

69. Nishiwaki-Ohkawa T, Yoshimura T: Molecular basis for regulating seasonal reproduction in vertebrates. Journal of Endocrinology. 2016, 229(3):R117-27.

70. Pittendrigh CS: On temporal organization in living systems. In: Harvey Lectures, 1961, p. 93-125. Academic Press, Inc., New York.

71. Foulkes NS, Whitmore D, Vallone D, Bertolucci C: Studying the Evolution of the Vertebrate Circadian Clock: The Power of Fish as Comparative Models. Adv Genet. 2016, 95:1-30.

72. Qian X, Ba Y, Zhuang Q, Zhong G: RNA-Seq technology and its application in fish transcriptomics. Omics: a journal of integrative biology. 2014, 18(2): 98-110.

73. Robinson N, Sahoo PK, Baranski M, Mahapatra KD, Saha JN, Das S, Mishra Y, Das P, Barman HK, Eknath AE: Expressed sequences and polymorphisms in rohu carp (Labeo rohita, Hamilton) revealed by mRNA-sEq. Marine biotechnology. 2012, 14(5):620-33.

74. Robinson N, Baranski M, Mahapatra KD, Saha JN, Das S, Mishra J, Das P, Kent M, Arnyasi M, Sahoo PK: A linkage map of transcribed single nucleotide polymorphisms in rohu (Labeo rohita) and QTL associated with resistance to Aeromonas hydrophila. BMC genomics. 2014, 15(1):541.

75. Skiba-Cassy S, Lansard M, Panserat S, Médale F: Rainbow trout genetically selected for greater muscle fat content display increased activation of liver TOR signaling and lipogenic gene expression. American Journal of Physiology-Regulatory, Integrative and Comparative Physiology. 2009, 297(5):R1421-9.

76. Hu G, Gu W, Sun P, Bai Q, Wang: Transcriptome analyses reveal lipid metabolic process in liver related to the difference of carcass fat content in rainbow trout (Oncorhynchus mykiss). International journal of genomics. 2016, 7281585 .

77. Asker N, Kristiansson E, Albertsson E, Larsson DJ, Förlin L: Hepatic transcriptome profiling indicates differential mRNA expression of apoptosis and immune related genes in eelpout (Zoarces viviparus) caught at Göteborg harbor, Sweden. Aquatic toxicology. 2013, 130:58-67.

78. Barber BJ, Blake NJ: Reproductive physiology. In: S.E. Shumway \& G.J. Parsons (eds.). Scallops: biology, ecology, and aquaculture. Elsevier, Amsterdam. 2006, 357-416.

79. Luna LG: Manual of histologic staining methods of the Armed Forces Institute of Pathology. 1968, 1-258 (New York: McGraw-Hill)

80. Andrews S: FastQC: a quality control tool for high throughput sequence data. 2010.

81. Bolger AM, Lohse M, Usadel B: Trimmomatic: a flexible trimmer for Illumina sequence data. Bioinformatics. 2014, 30:2114-2120.

82. Haas BJ, Papanicolaou A, Yassour M, Grabherr M, Blood PD, Bowden J, Couger MB, Eccles D, Li B, Lieber $M$, et al: De novo transcript sequence reconstruction from RNA-Seq: reference generation and 
analysis with Trinity. Nature protocols. 2013, 8(8):1494-1512.

83. Li B, Dewey CN: RSEM: accurate transcript quantification from RNA-Seq data with or without a reference genome. BMC bioinformatics. 2011, 12:323.

84. Robinson MD, McCarthy DJ, Smyth GK: edgeR: a Bioconductor package for differential expression analysis of digital gene expression data. Bioinformatics. 2010, 26:139-140.

85. Thiel T, Michalek W, Varshney R, Graner A: Exploiting EST databases for the development and characterization of gene-derived SSR-markers in barley (Hordeum vulgare L.). Theoretical and Applied Genetics. 2003, 106:411-422.

86. Li H, Durbin: Fast and accurate short read alignment with Burrows-Wheeler transform. Bioinformatics. 2009, 25:1754-1760.

87. Li H: A statistical framework for SNP calling, mutation discovery, association mapping and population genetical parameter estimation from sequencing data. Bioinformatics. 2011, 27:29872993.

88. Griffiths-Jones S, Grocock RJ, Van Dongen S, Bateman A, Enright AJ: miRBase: microRNA sequences, targets and gene nomenclature. Nucleic acids research. 2006, 34:D140-D144.

89. Enright AJ, John B, Gaul U, Tuschl T, Sander C, Marks DS: MicroRNA targets in Drosophila. Genome biology. 2003, 5:R1

90. Shannon P, Markiel A, Ozier O, Baliga NS, Wang JT, Ramage D, Amin N, Schwikowski B, Ideker T: Cytoscape: a software environment for integrated models of biomolecular interaction networks. Genome research. 2003, 13(11):2498-2504.

91. Untergasser A, Cutcutache I, Koressaar T, Ye J, Faircloth BC, Remm M, Rozen SG: Primer3-new capabilities and interfaces. Nucleic acids research. 2012, 40(15): e115-e115.

92. Pfaffl MW: A new mathematical model for relative quantification in real-time RT-PCR. Nucleic acids research. 2001, 29: e45-e45.

93. Bennett V, Lorenzo DN: Spectrin-and ankyrin-based membrane domains and the evolution of vertebrates. Curr Top Membr. 2013, 72:1-37.

94. Ferrari R, Forabosco P, Vandrovcova J, Botía JA, Guelfi S, Warren JD, Momeni P, Weale ME, Ryten M, Hardy J: Frontotemporal dementia: insights into the biological underpinnings of disease through gene co-expression network analysis. Molecular neurodegeneration. 2016, 11(1):21.

95. Herrero-Turrión MJ, Rodríguez-Martín I, López-Bellido, R, Rodríguez RE: Whole-genome expression profile in zebrafish embryos after chronic exposure to morphine: identification of new genes associated with neuronal function and mu opioid receptor expression. BMC genomics. 2014, 15:874.

96. Greenwood AK, Peichel CL: Social regulation of gene expression in threespine sticklebacks. PloS one. 2015, 10:e0137726.

97. Nonet ML: A window into domain amplification through Piccolo in teleost fish. G3: Genes, Genomes, Genetics. 2012, 2:1325-1339. 
98. Olave I, Wang W, Xue Y, Kuo A, Crabtree GR: Identification of a polymorphic, neuron-specific chromatin remodeling complex. Genes \& development. 2002, 16:2509-2517.

99. Heimel JA, Hermans JM, Sommeijer JP, Levelt CN: Genetic control of experience-dependent plasticity in the visual cortex. Genes, Brain and Behavior. 2008, 7:915-923.

100. Teng H, Cai W, Zhou L, Zhang J, Liu Q, Wang Y, Dai W, Zhao M, Sun Z: Evolutionary mode and functional divergence of vertebrate NMDA receptor subunit 2 genes. PloS one. 2010, 5(10):e13342.

101. Drew RE, Rodnick KJ, Settles M, Wacyk J, Churchill E, Powell MS, Hardy RW, Murdoch GK, Hill RA, Robison BD: Effect of starvation on transcriptomes of brain and liver in adult female zebrafish (Danio rerio). Physiological genomics. 2008, 35(3):283-295.

102. Guillot R, Cortés R, Navarro S, Mischitelli M, García-Herranz V, Sánchez E, Cal L, Navarro JC, Míguez $\mathrm{JM}$, Afanasyev S, et al: Behind melanocortin antagonist overexpression in the zebrafish brain: a behavioral and transcriptomic approach. Hormones and behaviour. 2016, 82:87-100.

103. Boothroyd CE, Wijnen H, Naef F, Saez L, Young MW: Integration of light and temperature in the regulation of circadian gene expression in Drosophila. PLoS genetics. 2007, 3:e54.

104. Ciampi R, Nikiforov YE: Alterations of the BRAF gene in thyroid tumors. Endocrine pathology. 2005, 16:163-171.

105. Li Z, Zheng W, Wang Z, Zeng Z, Zhan H, Li C, Zhou L, Yan C, Spitsbergen JM, Gong Z: A transgenic zebrafish liver tumor model with inducible Myc expression reveals conserved Myc signatures with mammalian liver tumors. Disease models \& mechanisms. 2013, 6(2):414-423.

106. Ahlemann M, Zeidler R, Lang S, Mack B, Münz M, Gires O: Carcinoma-associated elF3i overexpression facilitates mTOR-dependent growth transformation. Molecular carcinogenesis. 2006, 45(12):957-967.

107. Choudhuri A, Evans T, Maitra U: Non-core subunit elF3h of translation initiation factor elF3 regulates zebrafish embryonic development. Developmental Dynamics. 2010, 239:1632-1644.

108. Wiseman SB, He Y, Gamal-El Din M, Martin JW, Jones PD, Hecker M, Giesy JP: Transcriptional responses of male fathead minnows exposed to oil sands process-affected water. Comparative Biochemistry and Physiology Part C: Toxicology \& Pharmacology. 2013, 157(2):227-235.

109. Fujita M, Mitsuhashi H, Isogai S, Nakata T, Kawakami A, Nonaka I, Noguchi S, Hayashi YK, Nishino I, Kudo A: Filamin C plays an essential role in the maintenance of the structural integrity of cardiac and skeletal muscles, revealed by the medaka mutant zacro. Developmental biology. 2012, 361:79-89.

110. Shiraishi E, Hosseini H, Kang DK, Kitano T, Akiyama H: Nanosecond pulsed electric field suppresses development of eyes and germ cells through blocking synthesis of retinoic acid in Medaka (Oryzias latipes). PloS one. 2013, 8:e70670.

111. Adolfi MC, Herpin A, Regensburger M, Sacquegno J, Waxman JS, Schartl M: Retinoic acid and meiosis induction in adult versus embryonic gonads of medaka. Scientific reports. 2016, 6:34281.

112. Cao LX, Le Bousse-Kerdilès MC, Clay D, Oshevski S, Jasmin C, Krief P: Implication of a new molecule IK in CD34 + hematopoietic progenitor cell proliferation and differentiation. Blood. 1997, 89(10):3615-3623. 
113. Vacaru AM, Unlu G, Spitzner M, Mione M, Knapik EW, Sadler KC: In vivo cell biology in zebrafishproviding insights into vertebrate development and disease. J Cell Sci. 2014, 127(3):485-495.

114. Gu M, Lin G, Lai Q, Zhong B, Liu Y, Mi Y, Chen H, Wang B, Fan L, Hu C: Ctenopharyngodon idella IRF2 plays an antagonistic role to IRF1 in transcriptional regulation of IFN and ISG genes. Developmental \& Comparative Immunology. 2015, 49(1):103-112.

115. Klangnurak W, Tokumoto $\mathrm{T}$ : Fine selection of up-regulated genes during ovulation by in vivo induction of oocyte maturation and ovulation in zebrafish. Zoological Letters. 2017, 3:2.

116. Ribas LP, Planas JV, Barton B, Monetti C, Bernadini G, Saroglia M, Tort L, MacKenzie S: A differentially expressed enolase gene isolated from the gilthead sea bream (Sparus aurata) under high-density conditions is up-regulated in brain after in vivo lipopolysaccharide challenge. Aquaculture. 2004, 241(1-4):195-206.

117. Fort P, Blangy A: The evolutionary landscape of Dbl-like RhoGEF families: adapting eukaryotic cells to environmental signals. Genome Biology and Evolution. 2017, 9:1471-1486.

118. Barat A, Kumar R, Goel C, Singh AK, Sahoo PK: De novo assembly and characterization of tissuespecific transcriptome in the endangered golden mahseer, Tor putitora. Meta gene. 2016, 7:28-33.

119. Birk OS, Casiano DE, Wassif CA, Cogliati T: The LIM homeobox gene Lhx9 is essential for mouse gonad formation. Nature. 2000, 403:909-913.

120. Knoll-Gellida A, André M, Gattegno T, Forgue J, Admon A, Babin PJ: Molecular phenotype of zebrafish ovarian follicle by serial analysis of gene expression and proteomic profiling, and comparison with the transcriptomes of other animals. BMC genomics. 2006, 7(1):46.

121. Rhee JS, Kim BM, Kim RO, Choi BS, Choi IY, Lee YM, Lee JS: Analysis of expressed sequence tags from the liver and ovary of the euryhaline hermaphroditic fish, Kryptolebias marmoratus. Comparative Biochemistry and Physiology Part D: Genomics and Proteomics. 2011, 6(3):244-255.

122. Gouttenoire J, Valcourt U, Bougault C, Aubert-Foucher E, Arnaud E, Giraud L, Mallein-Gerin F: Knockdown of the intraflagellar transport protein IFT46 stimulates selective gene expression in mouse chondrocytes and affects early development in zebrafish. Journal of Biological Chemistry. 2007, 282:30960-30973.

123. Baumgart M, Groth M, Priebe S, Savino A, Testa G, Dix A, Ripa R, Spallotta F, Gaetano C, Ori M et al: RNA-seq of the aging brain in the short-lived fish $\mathrm{N}$. furzeri - conserved pathways and novel genes associated with neurogenesis. Aging Cell. 2014, 13:965-974.

124. Stacey NE, Pandey S: Effects of indomethacin and prostaglandins on ovulation of goldfish. Prostaglandins. 1975, 9:597-607.

125. Touhata K, Tanaka M, Toyohara H, Tanaka H, Sakaguchi M: Seasonal change in collagen content of red seabream muscle. Fisheries science. 2000, 66:553-557.

126. Palstra AP, Planas JV: Fish under exercise. Fish Physiology and Biochemistry. 2011, 37:259-272.

127. Hiramatsu N, Todo T, Sullivan CV, Schilling J, Reading BJ, Matsubara T, Ryu YW, Mizuta H, Luo W, Nishimiya O, et al: Ovarian yolk formation in fishes: Molecular mechanisms underlying formation of 
lipid droplets and vitellogenin-derived yolk proteins. General and comparative endocrinology. 2015, 221:9-15.

128. Bayne S, Li H, Jones ME, Pinto AR, van Sinderen M, Drummond A, Simpson ER, Liu JP: Estrogen deficiency reversibly induces telomere shortening in mouse granulosa cells and ovarian aging in vivo. Protein \& cell. 2011, 2(4):333-346.

129. Philip AM, Vijayan MM: Stress-immune-growth interactions: cortisol modulates suppressors of cytokine signaling and JAK/STAT pathway in rainbow trout liver. PloS one. 2015, 10:e0129299.

130. Fedorov VB, Goropashnaya AV, Tøien $\emptyset$, Stewart NC, Chang C, Wang H, Yan J, Showe LC, Showe MK, Barnes BM: Modulation of gene expression in heart and liver of hibernating black bears (Ursus americanus). BMC genomics. 2011, 12(1):171.

131. Komoroske LM, Connon RE, Jeffries KM, Fangue NA: Linking transcriptional responses to organismal tolerance reveals mechanisms of thermal sensitivity in a mesothermal endangered fish. Molecular ecology. 2015, 24:4960-4981.

132. Tingaud-Sequeira A, Forgue J, André M, Babin PJ: Epidermal transient down-regulation of retinolbinding protein 4 and mirror expression of apolipoprotein Eb and estrogen receptor 2a during zebrafish fin and scale development. Developmental dynamics. 2006, 235:3071-3079.

133. Yang D, Liu Q, Yang M, Wu H, Wang Q, Xiao J, Zhang Y: RNA-seq liver transcriptome analysis reveals an activated MHC-I pathway and an inhibited MHC-Il pathway at the early stage of vaccine immunization in zebrafish. BMC genomics. 2012, 13(1):319.

134. Jackson B, Brocker C, Thompson DC, Black W, Vasiliou K, Nebert DW, Vasiliou V: Update on the aldehyde dehydrogenase gene (ALDH) superfamily. Human genomics. 2011, 5(4):283.

135. Groh KJ, Nesatyy VJ, Segner H, Eggen RI, Suter MJF: Global proteomics analysis of testis and ovary in adult zebrafish (Danio rerio). Fish physiology and biochemistry. 2011, 37:619-647.

136. Um HN, Han JM, Hwang JI, Hong SI, Vaudry H, Seong JY: Molecular coevolution of kisspeptins and their receptors from fish to mammals. Annals of the New York Academy of Sciences. 2012, 1200(1):67-74.

137. Chen YJ, Zhang TY, Chen HY, Lin SM, Luo L, Wang DS: Simultaneous stimulation of glycolysis and gluconeogenesis by feeding in the anterior intestine of the omnivorous GIFT tilapia, Oreochromis niloticus. Biology Open. 2017, 6(6):818-824.

138. Liu C, Yao J, Wei Q, Xing G, Cao X: Spatial and temporal expression patterns of Osbpl2a and Osbpl2b during zebrafish embryonic development. International journal of pediatric otorhinolaryngology. 2016, 84:174-179.

\section{Tables}




\begin{tabular}{|ll|}
\hline \multicolumn{2}{|l|}{ Table 1. De novo assembled statistics of Rohu transcriptome (All IGA vs. all PSR) } \\
\hline Total trinity transcripts & 440665 \\
\hline Total trinity genes & 336520 \\
\hline Percent GC & 42.94 \\
\hline Contig N50 & $1850 \mathrm{bp}$ \\
\hline Minimum contig length & $201 \mathrm{bp}$ \\
\hline Maximum contig length & $19331 \mathrm{bp}$ \\
\hline Median contig length & $381 \mathrm{bp}$ \\
\hline Average contig & $867.45 \mathrm{bp}$ \\
\hline Total assembled bases & 382252837 \\
\hline
\end{tabular}

Table 2. Number of upregulated and downregulated DEGs from IGA[BR] vs. PSR[BR], IGA[PIT] vs. PSR[PIT], IGA[OVA] vs. PSR[OVA] and IGA[LIV] vs. PSR[LIV]

\begin{tabular}{llll} 
Datasets & Upregulated & Downregulated & Total DEGs \\
\hline IGA[BR] vs. PSR[BR] & 14647 & 21193 & 35840 \\
\hline IGA[PIT] vs. PSR[PIT] & 10050 & 11717 & 21767 \\
\hline IGA[OVA] vs. PSR[OVA] & 17194 & 13903 & 31097 \\
\hline IGA[LIV] vs. PSR[LIV] & 6786 & 7772 & 14558
\end{tabular}

Table 3. Sequence similarity to know sequence, annotation and mapping unigenes.

\begin{tabular}{|lllll|} 
& $\begin{array}{l}\text { IGA[BR] vs. } \\
\text { PSR[BR] }\end{array}$ & $\begin{array}{l}\text { IGA[PIT] vs. } \\
\text { PSR[PIT] }\end{array}$ & $\begin{array}{l}\text { IGA[OVA] vs. } \\
\text { PSR[OVA] }\end{array}$ & \multicolumn{1}{l|}{$\begin{array}{l}\text { IGA[LIV] vs. } \\
\text { PSR[LIV] }\end{array}$} \\
$\begin{array}{l}\text { Total } \\
\text { Sequences }\end{array}$ & 35840 & 21767 & 31097 & 14558 \\
\hline $\begin{array}{l}\text { With } \\
\text { InterProScan }\end{array}$ & 35829 & 21765 & 31089 & 14558 \\
\hline With Blast Hits & 28411 & 18369 & 25773 & 12584 \\
\hline With Mapping & 22625 & 15306 & 21196 & 10708 \\
\hline $\begin{array}{l}\text { With } \\
\text { Annotation }\end{array}$ & 17010 & 11986 & 15892 & 8458 \\
\hline
\end{tabular}


Table 4. List of mature miRNAs of nine fish species which regulate transcripts at tissue specific stages IGA[BR] vs. PSR[BR], IGA[PIT] vs. PSR[PIT], IGA[OVA] vs. PSR[OVA] and IGA[LIV] vs. PSR[LIV]

\begin{tabular}{|lllllll|}
\hline $\begin{array}{l}\text { S. } \\
\text { No }\end{array}$ & Species & $\begin{array}{l}\text { Mature } \\
\text { miRNA }\end{array}$ & $\begin{array}{l}\text { IGA[BR] vs. } \\
\text { PSR[BR] }\end{array}$ & $\begin{array}{l}\text { IGA[LIV] vs. } \\
\text { PSR[LIV] }\end{array}$ & $\begin{array}{l}\text { IGA[OVA] vs. } \\
\text { PSR[OVA] }\end{array}$ & $\begin{array}{l}\text { IGA[PIT] vs. } \\
\text { PSR[PIT] }\end{array}$ \\
\hline 1 & Danio rerio & 350 & $163(761)$ & $140(452)$ & $152(668)$ & $128(549)$ \\
\hline 2 & Fugu rubripes & 108 & $58(287)$ & $43(176)$ & $54243)$ & $41(223)$ \\
\hline 3 & $\begin{array}{l}\text { Cyprinus carpio } \\
4\end{array}$ & 146 & $79(339)$ & $64(224)$ & $77(323)$ & $62(256)$ \\
\hline 5 & $\begin{array}{l}\text { Hippoglossus } \\
\text { hippoglossus }\end{array}$ & 37 & $19(229)$ & $14(148)$ & $21(182)$ & $14(167)$ \\
\hline 6 & $\begin{array}{l}\text { Ictalurus } \\
\text { punctatus }\end{array}$ & 205 & $108(620)$ & $93(358)$ & $113(559)$ & $98(147)$ \\
\hline 7 & $\begin{array}{l}\text { Oryzias latipes } \\
\text { Paralichthys }\end{array}$ & 146 & $61(243)$ & $47(174)$ & $64(257)$ & $50(215)$ \\
\hline 8 & $\begin{array}{l}\text { olivaceus } \\
\text { Salmo salar }\end{array}$ & 498 & $228(1002)$ & $185(556)$ & $210(862)$ & $181(752)$ \\
\hline 9 & $\begin{array}{l}\text { Tetraodon } \\
\text { nigroviridis }\end{array}$ & 109 & $60(293)$ & $46(179)$ & $57(279)$ & $43(232)$ \\
\hline
\end{tabular}




\begin{tabular}{|c|c|c|c|c|}
\hline & $\begin{array}{l}\text { IGA[BR] vs. } \\
\text { PSR[BR] }\end{array}$ & $\begin{array}{l}\text { IGA[PIT] vs. } \\
\text { PSR[PIT] }\end{array}$ & $\begin{array}{l}\text { IGA[OVA] vs. } \\
\text { PSR[OVÁ] }\end{array}$ & $\begin{array}{l}\text { IGA[LIV] vs. } \\
\text { PSR[LIV] }\end{array}$ \\
\hline Sequences examined & 35840 & 21767 & 31097 & 14558 \\
\hline Identified SSRs & 19633 & 12899 & 16461 & 8874 \\
\hline SSR containing sequences & 13602 & 8784 & 11385 & 5979 \\
\hline $\begin{array}{l}\text { Sequences containing more } \\
\text { than one SSR }\end{array}$ & 4209 & 2837 & 3520 & 1975 \\
\hline $\begin{array}{l}\text { SSRs present in compound } \\
\text { formation }\end{array}$ & 1202 & 741 & 997 & 526 \\
\hline Mono- & 11173 & 7498 & 9735 & 5492 \\
\hline Di- & 5717 & 3603 & 4465 & 2174 \\
\hline Tri- & 2319 & 1563 & 1975 & 1075 \\
\hline Tetra- & 406 & 221 & 269 & 123 \\
\hline Penta- & 12 & 7 & 10 & 5 \\
\hline Hexa- & 6 & 7 & 7 & 5 \\
\hline
\end{tabular}


Table 6. Role of different hub genes identified in rohu fish brain

\begin{tabular}{|lll}
\hline Gene & Description & Reference \\
$\begin{array}{lll}\text { ank1b and } \\
\text { ank3b }\end{array}$ & $\begin{array}{l}\text { Ankryn (ank) gene: Regulatory protein } \\
\text { interacting with TF in cis and trans regulatory } \\
\text { mode optimizing various physiological } \\
\text { function via voltage-gated sodium channels, } \\
\text { and KCNQ2/3 channels which is fast and } \\
\text { precise as regulatory signaling }\end{array}$ & [93] \\
OPTN & $\begin{array}{l}\text { Optinuerin (OPTN): Produced in } \\
\text { neuroendocrine tissues which modulates beta- } \\
\text { amyloid converting enzyme 1 involved in } \\
\text { production of amyloid-beta }\end{array}$ & [94] \\
rims1 gene & $\begin{array}{l}\text { Regulating synaptic membrane exocytosis 1 } \\
\text { (rims1) gene: It is a RAS gene superfamily } \\
\text { member which regulates neurotransmitter } \\
\text { release by controlling synaptic vesicle } \\
\text { exocytosis and dendrite formation by } \\
\text { melanocytes }\end{array}$ & https://ghr.nlm.nih.gov/gene/RIMS1 \\
\hline
\end{tabular}

PCMT Protein-L-Isoaspartate (D-Aspartate) OMethyltransferase (PCMT) gene plays role in

[95] monoaminergic neuromodulation, glutamatergic neurotransmission and neuronal function in development

fryA gene Furry homolog (fryA) gene regulates cell proliferation controlling structural integrity with polarity of spindle, involved in neural development and cell adhesion. It also regulates sensory signaling involved in reproductive behavior in zebrafish and sticklebacks fish

PCLOB Piccolo (PCOLB) gene regulates

Gene neurotransmitter secretion by controlling release of synaptic vesicles in salmon and zebrafish

SMAARCC2 SWI/SNF Related, Matrix Associated, Actin Dependent Regulator Of Chromatin Subfamily [98] C Member 2 (SMARCC2) gene is a member of the SWI/SNF family having helicase and ATPase activities regulating transcription by altering the chromatin structure

STCH gene This is a Hsp70 family gene reported to be a promising candidate gene for sensing incubation time by ocular dominance and cortical plasticity mediating visual stimuli

AATK gene Apoptosis associated tyrosine kinase (AATK) [97]

[96] gene: This gene has epigenetic regulation associated with growth and differentiation. Regulates GRIN2 gene, which is one of the key genes of learning and memory in zebrafish 

Controls lipid metabolism, biosynthesis,
proteolysis and gluconeogenesis in liver of zebrafish

[101]

WDFY gene Regulates feeding behaviour and growth involved in brain-pituitary axis of zebrafish

[102]

PHF24

A well conserved gene across various phyla, involved in integration of light and temperature in the regulation of circadian gene expression

[103] 
Table 7. Role of different hub genes identified in rohu fish pituitary gland

Gene Description

Reference

AKAP9 A-kinase anchoring protein 9 (AKAP9) gene is involved in ovarian growth and gametogenesis by MAPK signaling pathway

ANKHD1 Ankyrin repeat and KH domain containing 1 (ANKHD1) stimulates liver growth in vitellogenesis period of zebrafish

EIF3i Eukaryotic translation initiation factor $i(E I F 3 i)$ is involved in the initiation process of protein translation. Overexpression leads to increase in cell size and proliferation. In zebrafish, it regulates development of the brain, heart, vasculature, and lateral line.

Myo1b Myosin IB (Myo1B) gene affects BPGL axis by directly affecting liver metabolism and growth in cyprinid fish, fathead minnow

FLNA Filamin A (FLNA) regulates neuro-epilthelia cell proliferation and differentiation by regulating actin cytoskeleton and transmembrane receptor complex in cardiac and skeletal muscles development in medaka fish

dpp6B

Dipeptidyl-peptidase (dpp6B) gene is involved in retinoic acid pathway controling development of eye and germ cells in medaka fish. Retinoic acid pathway controls gametogenesis.

Ik gene Ik Gene codes for protein Red. This gene is present in zebrafish. It is involved in cell proliferation and differentiation

LAMP2 Pituitary being endocrine gland has several secretory activities. Lamp2 has been reported to control such activities of lysosomes in zebrafish

IRF2 BP Iterferon Regulatory Factors (IRFs): In grass carp and zebrafish, this highly conserved gene has been reported to modulate innate immune response.

Seasonality in breeding of fish is highly correlated with such immunity

ZGC ZGC gene is involved in oocyte maturation and ovulation in zebrafish

Gene

CMYCB $\quad$ MYCB gene is involved in neuroendocrine secretion in brain and physiological regulation in liver, heart, kidney in fish (European sea bass) affecting growth and differentiation

ARHGEF ARHGEF is also known as Rho Guanine Nucleotide Exchange Factor gene family which is present in all eukaryotes including jawless (Lampreys, Agnatha) as well as jaw (cartilaginous and boney) fishes. These are the adaptive cell signaling mediators of environmental signals in mediating seasonality

DNAJC Also known as HSP 40 play major role in immune responses and their overexpression in liver is associated with defense mechanism

LIMA1 LIM Domain And Actin Binding 1 (LIMA1) gene is associated with nuclear

and receptor essential for gonado-genesis

LIMA1A

splice

variant 
Table 8. Role of different hub genes identified in rohu fish gonad

$\begin{array}{ll}\text { Gene } & \text { Description } \\ \text { ZGC gene } & \text { ZGC gene is involved in oocyte maturation and ovulation in zebrafish } \\ \text { family } & \end{array}$

ZAR1 Zar1 is highly conserved gene also present in zebrafish, involved in growth of ovarian follicles

NASP nuclear autoantigenic sperm protein:Expression of zona pellucida protein of primary oocytes and cell cycle regulation in zebrafish is associated with NASP gene. This gene is also reported to promote female development by repressing male-specific genes

Col12A1: This is a signalling molecule associated with chondrocyte differentiation Collagen especially where collagen molecules are used in tissue remodeling during

Type XII

Alpha 1 physiological growth and differentiation in zebrafish

Chain

SCML4 (Sex Comb On Midleg Like)

ptgdsb

Prostaglandin D2 Synthase: This gene is involved in synthesis of prostaglandins which controls spawning by stimulating contraction of smooth muscles leading to ovulation in goldfish

Col $6 a 3$

Collagen Type VI Alpha 3 Chain;There is seasonal change in collagen content in muscles of fish synchronised with swimming ability. In farm SCML4 is differentially expressed and its GRN study has revealed its role in development of optic, retina and olfactory epithelia with reproductive seasonality in teleost fish fish,swimming exercise is reported to control puberty.

CDC42 gene Cell Division Cycle 42: Fish egg yolk mainly contains vitellogenins, synthesized in liver, growing oocytes takes it from circulation by receptormediated endocytosis in oocyte growth

ACD
Adrenocortical dysplasia homolog (ACD), Shelterin Complex Subunit And Telomerase Recruitment:

This gene controls telomeric elongation mediating mitogenic actions of estrogen in granulosa cells for ovarian growth with season 
Table 9. Role of different hub genes identified in rohu fish liver

\begin{tabular}{|c|c|c|}
\hline Gene & Description & Reference \\
\hline JAK1 gene & $\begin{array}{l}\text { In pre- spawning, JAK/STAT signaling pathway is down } \\
\text { regulated but in spawning phase, it is up regulated for growth } \\
\text { and increase in innate immunity of Rainbow trout fish }\end{array}$ & [129] \\
\hline PCK1 & $\begin{array}{l}\text { PCK1 is reported to have seasonal expression in liver of } \\
\text { animals. In fish,this gene is associated with regulation of } \\
\text { gluconeogenesis, oxidative phosphorylation and growth. }\end{array}$ & {$[130,131]$} \\
\hline \multirow[t]{2}{*}{ RABGAP } & RAB GTPase Activating Protein & [132] \\
\hline & $\begin{array}{l}\text { This gene is associated with seasonal apolipoprotein } \\
\text { production in liver of teleost fish }\end{array}$ & \\
\hline \multirow[t]{2}{*}{ MHC1 uja } & Major Histocompatibility Complex, Class I & [133] \\
\hline & This gene is associated with teleost immune responses & \\
\hline \multirow[t]{2}{*}{ ALDH5a1 } & Aldehyde Dehydrogenase 5 Family Member A1 & [134] \\
\hline & $\begin{array}{l}\text { This gene is highly conserved from fish to mammal and } \\
\text { associated with seasonal changes in retinoic acid, betaine and } \\
\text { gamma-aminobutyric acid production in fish liver }\end{array}$ & \\
\hline $\begin{array}{l}\text { PMT (mitogenic): } \\
\text { Protein O- } \\
\text { Mannosyltransferase }\end{array}$ & $\begin{array}{l}\text { In zebrafish, it controls apoptotic signaling mechanisms, } \\
\text { immune response and homeostasis in unfavourable } \\
\text { environmental stimuli or unfavourable period for breeding, thus } \\
\text { it plays role in synchronising the liver activity with environment } \\
\text { and seasonality }\end{array}$ & [135] \\
\hline $\begin{array}{l}\text { pSAT1 is similar to } \\
\text { GPR54 }\end{array}$ & $\begin{array}{l}\text { Fish GPR54-1 contains PSAT1 loci, there is evolutionary } \\
\text { propinquity between GPR54 and kisspeptin genes, later is well } \\
\text { known for controling seasonality }\end{array}$ & [136] \\
\hline G6PCA & $\begin{array}{l}\text { G6PCA is associated with JAK-STAT5 signalling pathway } \\
\text { operating in hepatocytes having glycolysis and } \\
\text { gluconeogenesis in tilapia fish }\end{array}$ & [137] \\
\hline OSBPL2B & $\begin{array}{l}\text { OSBPL2B protein is involved in regulation of cholesterol } \\
\text { trafficking and intracellular transport of lipids in zebrafish }\end{array}$ & [138] \\
\hline
\end{tabular}


Table 10. Similarity of rohu biological clock gene across different classes of chordates showing extent of conservation

PM: Petromyzon marinus; RT: Rhincodon typus (whale shark); DR: Danio rerio (zebrafish); CC: Cyprinus carpio (common carp); XT: Xenopus tropicalis (tropical clawed frog); GG: Gallus gallus (chicken); AC: Anolis carolinensis (green anole); OA: Ornithorhynchus anatinus (platypus); MD: Monodelphis domestica (gray short-tailed opossum); OvA: Ovis aries (sheep)

\section{SI Biological Clock Gene Identity in Percentage}

No. Name

\begin{tabular}{|c|c|c|c|c|c|c|c|c|c|c|c|}
\hline & & PM & RT & DR & CC & XT & GG & $A C$ & OA & MD & OvA \\
\hline 1 & Bmal2 & 100 & 76 & 93 & 94 & 79 & 76 & 74 & 75 & 77 & 76 \\
\hline 2 & clock & 81 & 78 & 97 & 96 & 81 & 86 & 90 & 83 & 82 & 86 \\
\hline 3 & cry 1 & 100 & 78 & 90 & 81 & 81 & 80 & 79 & 84 & 81 & 80 \\
\hline 4 & cry2 & 100 & 77 & 90 & 96 & 82 & 82 & 78 & 83 & 84 & 86 \\
\hline 5 & fox 12 & 100 & 83 & 86 & 85 & 85 & 90 & 80 & 85 & 85 & 87 \\
\hline 6 & $G N R H$ & 100 & 72 & 92 & 84 & 71 & 75 & 69 & 83 & 75 & 83 \\
\hline 7 & kisspeptin & 90 & 91 & 85 & 86 & 93 & 93 & 90 & 85 & 84 & 89 \\
\hline 8 & $L H$ & 89 & 67 & 76 & 83 & 66 & 68 & 67 & 70 & 67 & 68 \\
\hline 9 & PER1 & 100 & 72 & 85 & 90 & 81 & 71 & 88 & 77 & 79 & 80 \\
\hline 10 & Per2 & 100 & 83 & 81 & 89 & 78 & 77 & 81 & 78 & 77 & 78 \\
\hline 11 & Per3 & 100 & 89 & 88 & 90 & 77 & 91 & 77 & 80 & 85 & 79 \\
\hline 12 & esr1a & 95 & 83 & 84 & 91 & 87 & 86 & 82 & 84 & 84 & 85 \\
\hline 13 & $P V R$ & 100 & 77 & 84 & 90 & 73 & 70 & 75 & 74 & 81 & 68 \\
\hline 14 & Bty & 94 & 69 & 85 & 87 & 75 & 88 & 77 & 69 & 66 & 70 \\
\hline 15 & wisp 1 & 100 & 73 & 89 & 85 & 76 & 71 & 75 & 81 & 76 & 77 \\
\hline 16 & mdka & 100 & 95 & 84 & 89 & 72 & 81 & 76 & 70 & 89 & 73 \\
\hline 17 & $a m h$ & 88 & 91 & 97 & 87 & 91 & 82 & 83 & 88 & 93 & 91 \\
\hline 18 & ependymin & 100 & 77 & 90 & 92 & 75 & 76 & 76 & 88 & 70 & 72 \\
\hline 19 & CaMK2 & 77 & 81 & 83 & 90 & 85 & 84 & 83 & 82 & 84 & 84 \\
\hline 20 & ehmt1 & 100 & 80 & 89 & 84 & 75 & 77 & 80 & 79 & 75 & 80 \\
\hline 21 & ehmt2 & 100 & 87 & 91 & 88 & 73 & 79 & 77 & 80 & 77 & 80 \\
\hline 22 & racgap1 & 100 & 73 & 81 & 85 & 75 & 79 & 76 & 81 & 64 & 77 \\
\hline 23 & $f s t / 3$ & 100 & 69 & 90 & 87 & 81 & 72 & 93 & 76 & 72 & 80 \\
\hline
\end{tabular}




\begin{tabular}{|llllllllllll|}
\hline 24 & $f s t / 4$ & 93 & 73 & 75 & 92 & 66 & 69 & 83 & 69 & 90 & 74 \\
\hline 25 & $f s t / 5$ & 89 & 65 & 90 & 89 & 64 & 67 & 67 & 67 & 68 & 67 \\
\hline 26 & prdm & 100 & 81 & 72 & 85 & 70 & 75 & 76 & 74 & 71 & 73 \\
\hline 27 & Otx & 100 & 70 & 93 & 96 & 73 & 72 & 73 & 81 & 71 & 71 \\
\hline 28 & Myc & 100 & 79 & 88 & 93 & 76 & 78 & 77 & 69 & 71 & 80 \\
\hline 29 & srebf1 & 100 & 75 & 89 & 87 & 78 & 78 & 76 & 82 & 80 & 75 \\
\hline 30 & pac & 84 & 85 & 85 & 90 & 84 & 83 & 85 & 84 & 89 & 85 \\
\hline 31 & picalm & 93 & 86 & 86 & 92 & 80 & 81 & 80 & 79 & 81 & 83 \\
\hline 32 & aanat & 100 & 69 & 88 & 90 & 90 & 76 & 71 & 70 & 69 & 70 \\
\hline
\end{tabular}

\section{Supplementary Information}




\section{Supplementary Description of Contents \\ Files}

Supplementary Heat map, MA and Volcano plots of 4 sets of BPGL differential expressed genes.

file 1

Supplementary figure 1a: Heatmap for the expression profiling showing hierarchical clustering of DEGs of A) IGA[BR] vs. PSR[BR]; B) IGA[PIT] vs. PSR[PIT];

C) IGA[OVA] vs. PSR[OVA]; D) IGA[LIV] vs. PSR[LIV]

Supplementary figure $1 \mathrm{~b}: \mathrm{MA}$ and Volcano plots of differentially expressed genes of A) IGA[BR] vs. PSR[BR]; B) IGA[PIT] vs. PSR[PIT]; C) IGA[OVA] vs. PSR[OVA]; D) IGA[LIV] vs. PSR[LIV] (red color dots are differentially expressed and black color dot represents the Non-DEGs).

Supplementary file 2

Supplementary file 3

Supplementary file 4

Supplementary file 5

Supplementary file 6

Supplementary file 7

Supplementary file 8

Supplementary file 9

Supplementary file 10
Blast Results and expression values of 4 sets of BPGL differential expressed genes.

The gene ontology distribution of DEGs into biological process, Molecular function and cellular components.

KEGG pathways identified from 4 sets of BPGL differential expressed genes.

Transcription factor identification from BPGL differential expressed genes.

MiRNA targets identified from BPGL differential expressed genes.

Various species' miRNAs characterized during different developmental stage/ tissue/process.

Simple sequence repeats mined from de novo transcriptome assembly of rohu as well as 4 sets of BPGL differential expressed genes.

Single nucleotide polymorphism identified form summer and winter samples against Danio rerio genome and de novo transcriptome assembly of rohu

Gene regulatory network with hub genes identified in rohu fish BPGL differential expressed genes. Green color represents upregulated and red is downregulated.

Supplementary figure 10a: Gene regulatory network with hub genes identified in rohu fish brain

Supplementary figure 10b: Gene regulatory network with hub genes identified in rohu fish pituitary

Supplementary figure 10c: Gene regulatory network with hub genes identified in rohu fish gonad

Supplementary figure 10d: Gene regulatory network with hub genes identified in rohu fish liver

Supplementary file 11

qRT-PCR analysis of randomly selected rohu transcripts. 
Supplementary Extent of conservation of 32 biological clock genes in 10 different species. file 12

\section{Figures}

1(A)

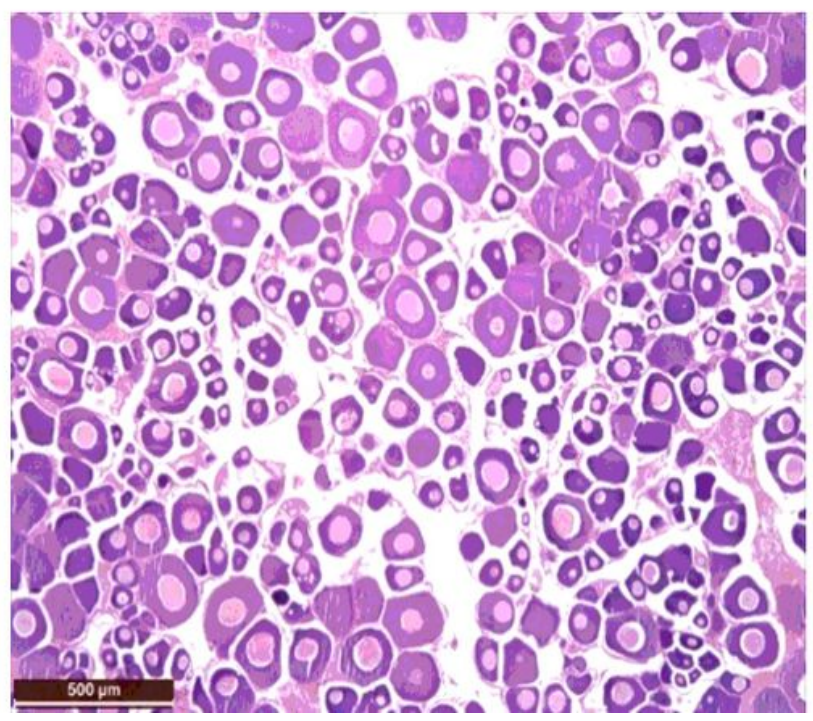

1(B)

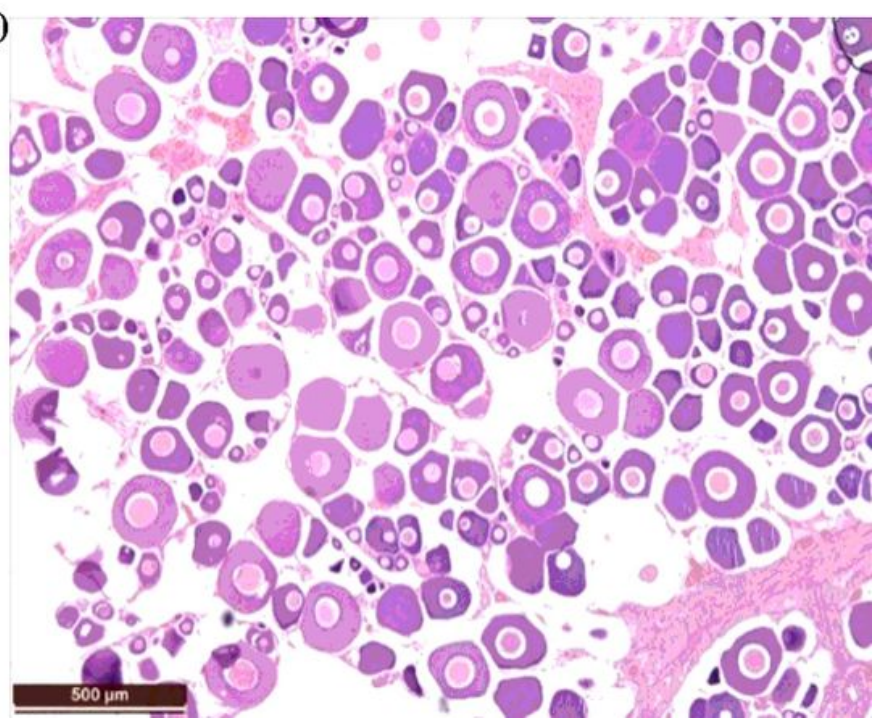

Figure 1

Histological photomicrographs of two physiologically contrasting phases i.e., PSR and IGA (1(A). PSR phase having both primary and secondary oocytes; 1 (B). IGA phase having primary oocyte growth phase, with initiation of nuclear condensation) 


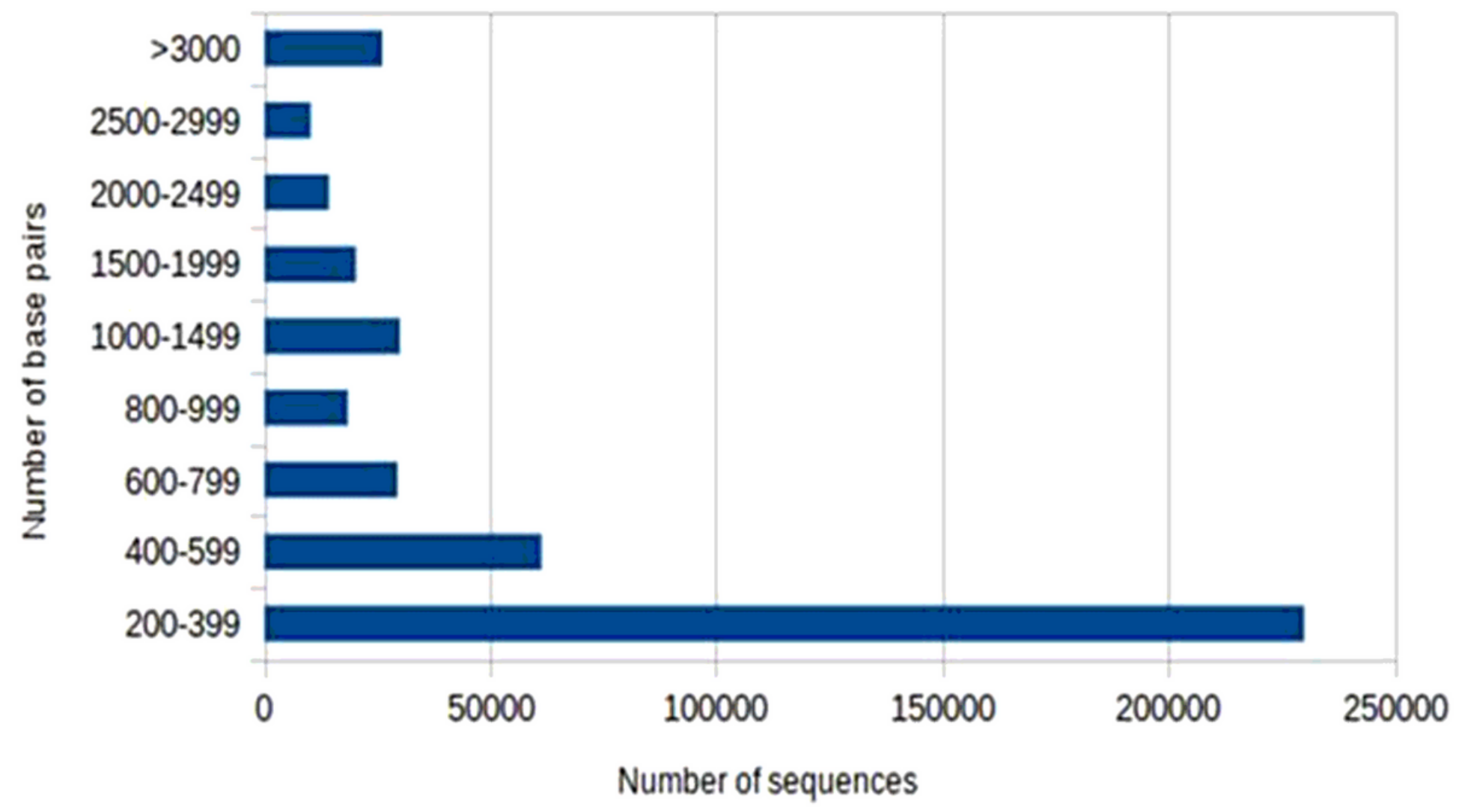

Figure 2

Sequence length distribution of the data

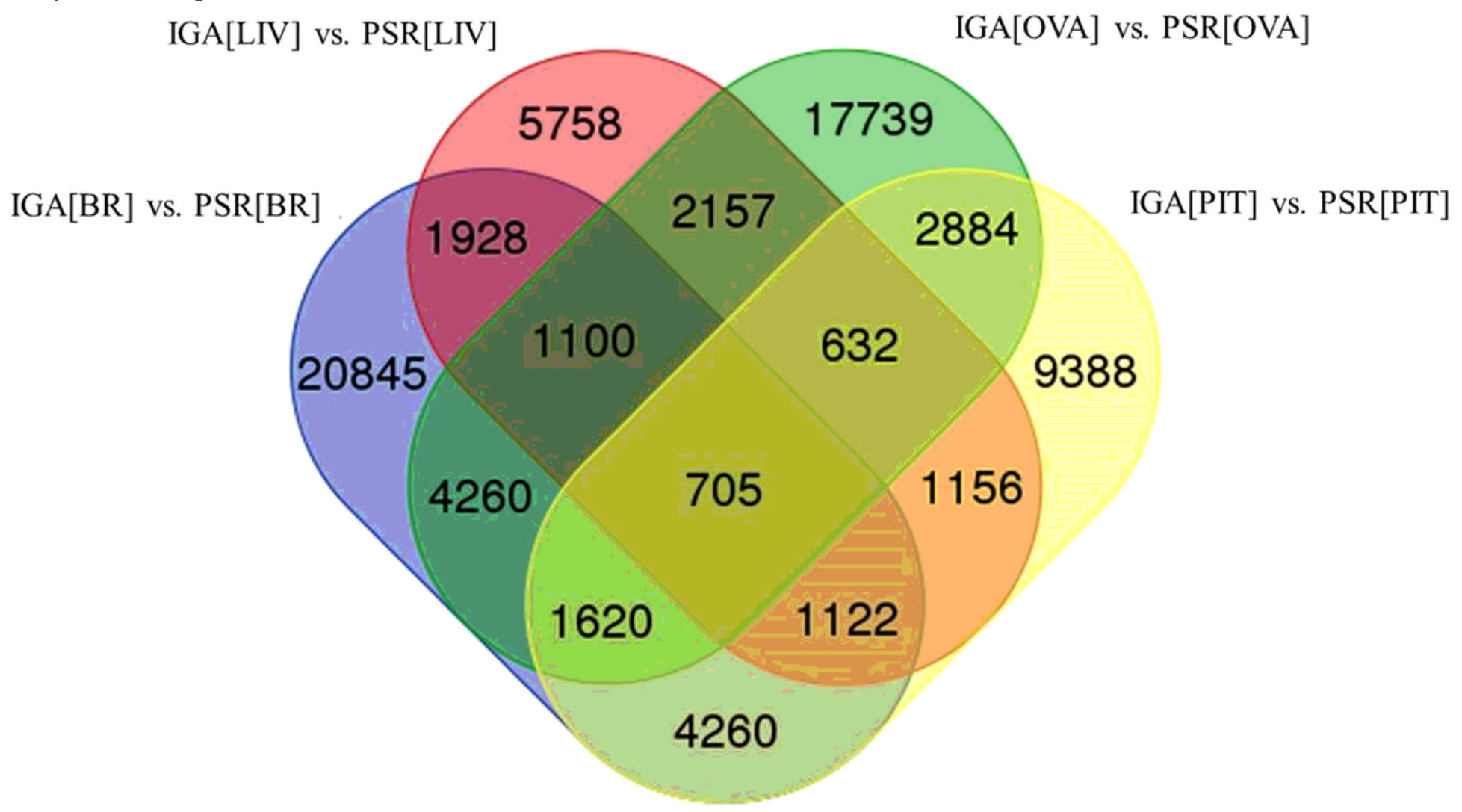

Figure 3 
Venn diagram to identify the unique and common unigenes among all tissue specific differentially expressed genes

IGA[LIV] vs. PSR[LIV]

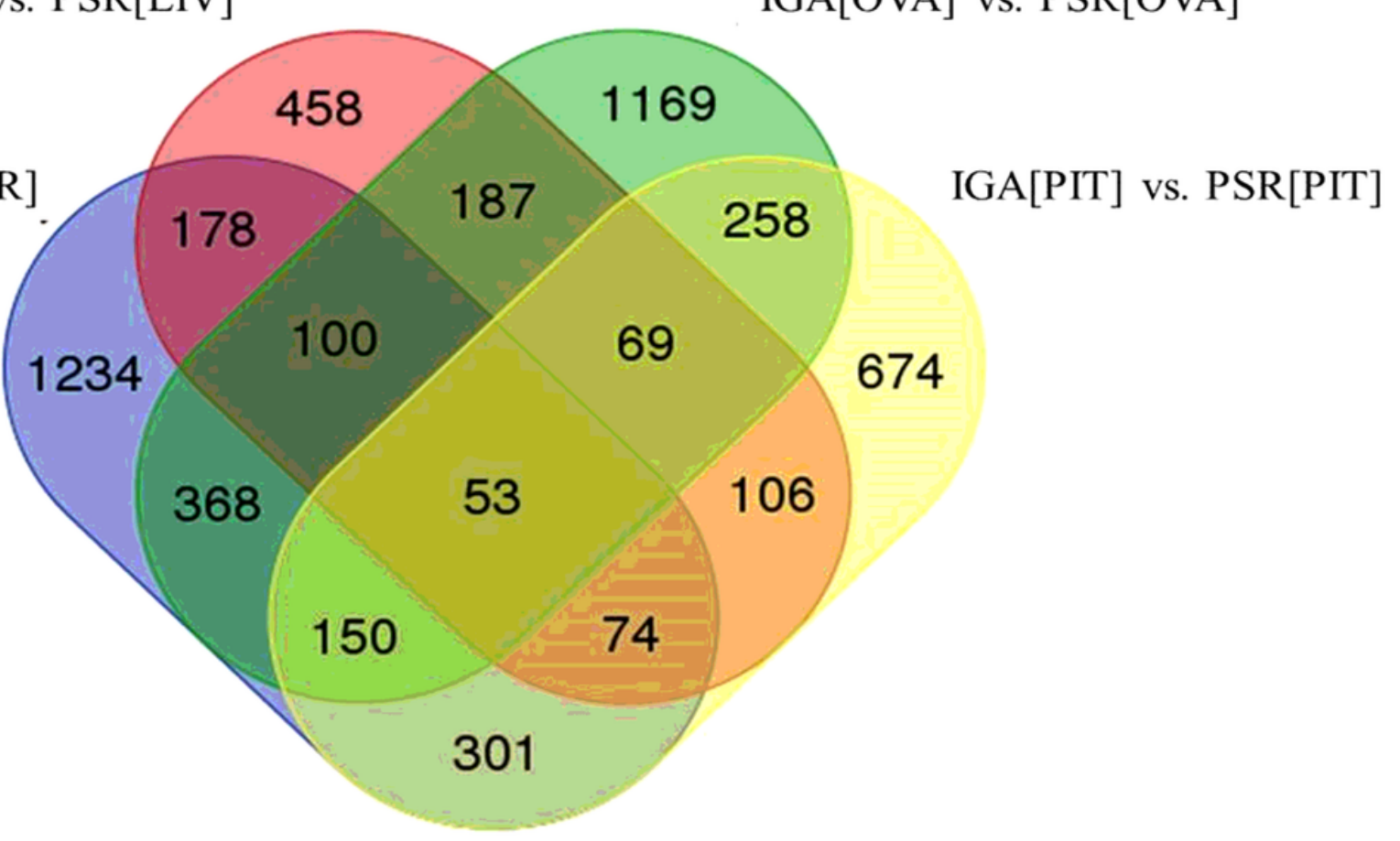

Figure 4

Venn diagram of transcription factors in all the tissue specific 


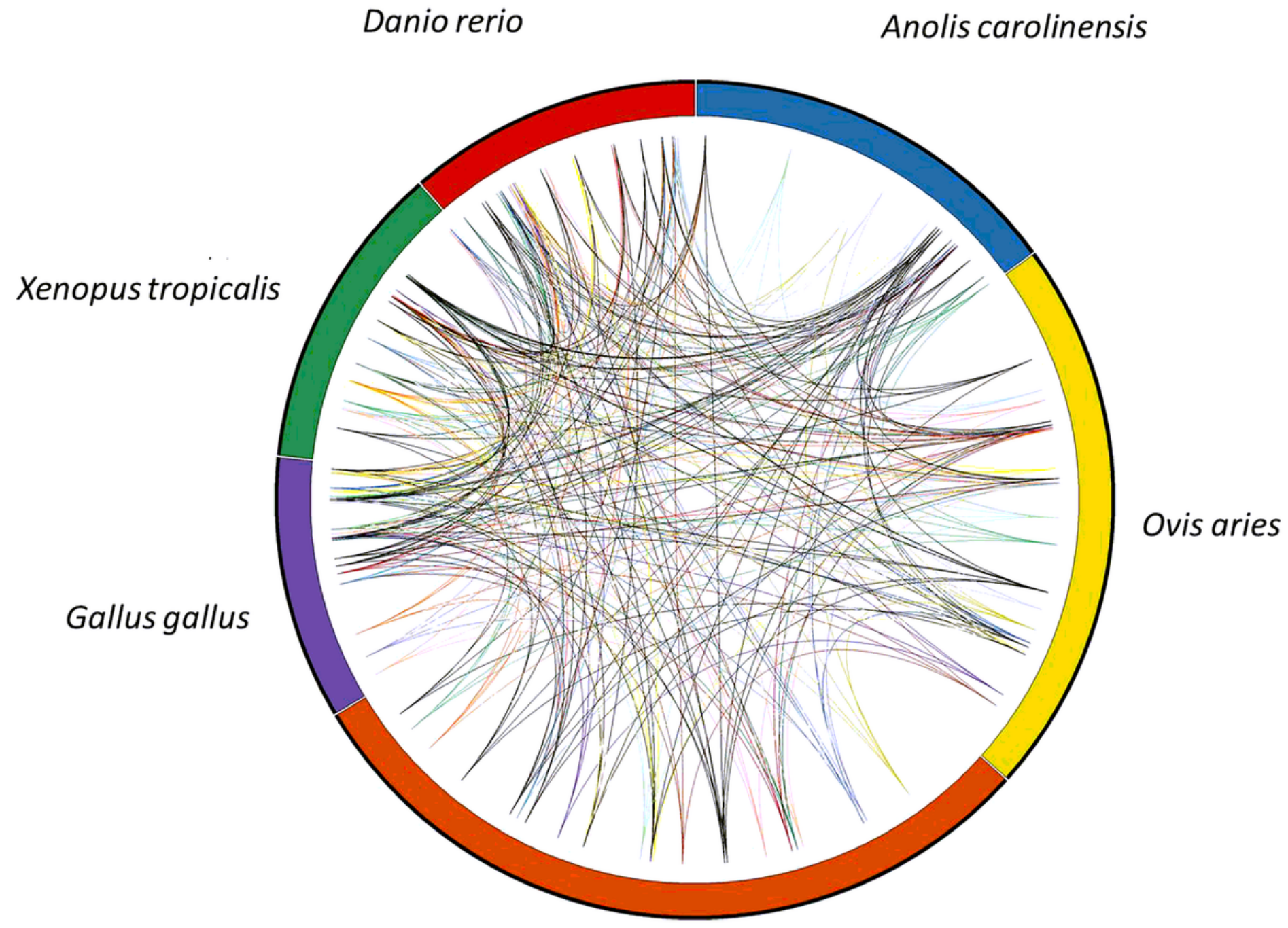

Monodelphis domestica

Figure 5

Extent of rohu biological clock gene conservation across different classes of chordates

\section{Supplementary Files}

This is a list of supplementary files associated with this preprint. Click to download.

- SupplementrayMaterial.doc

- Supplementaryfile1.doc

- Supplementaryfile2.xlsx

- Supplementaryfile3.doc

- Supplementaryfile4.xlsx

- Supplementaryfile5.xlsx 
- Supplementaryfile6.xlsx

- Supplementaryfile7.doc

- Supplementaryfile8.xlsx

- Supplementaryfile9.xlsx

- Supplementaryfile10.doc

- Supplementaryfile11.xlsx

- Supplementaryfile12.xIsx 